\title{
¿REGENERACIÓN DEMOCRÁTICA? ALGUNAS REFLEXIONES SOBRE LA NUEVA LEY ORGÁNICA 4/2013, DE 28 DE JUNIO, DE REFORMA DEL CONSEJO GENERAL DEL PODER JUDICIAL
}

\author{
ROSA M. ${ }^{a}$ FERNÁNDEZ RIVEIRA
}


SUMARIO

I. INTRODUCCIÓN. II. LA NUEVA LEY ORGÁNICA 4/2013, DE 28 DE JUNIO, DE REFORMA DEL CONSEJO GENERAL DEL PODER JUDICIAL: CONTEXTO Y GESTACIÓN DE LA REFORMA; a) El «sudoku» de la entrada en vigor; b) Flecos normativos resueltos con una ley orgánica de artículo único; c) El «corta de aquí y pega allá»; III. CONTENIDO DE LA REFORMA: 1. Atribuciones del Consejo; 2. Elección de los vocales; 3. Eliminación de las situaciones de bloqueo en la renovación del CGPJ; 4. Ejercicio a tiempo parcial del cargo de vocal; 5. La nueva estructura y reparto de competencias entre los órganos del CGPJ, en especial, su Vicepresidente (del TS).

a) Una Comisión Permanente fuerte y protagonista y con vocales en «dedicación exclusiva»; b) Un Vicepresidente del Tribunal Supremo «alter ego» del Presidente del CGPJ; c) Un Consejo «profesionalizado» a través de Letrados del Consejo General del Poder Judicial; d) La aplicación de la regla de la mayoría simple con carácter general. El nuevo régimen de los Actos del Consejo. 6. Transformación de la Comisión Disciplinaria. El nuevo órgano: el Promotor de la Acción Disciplinaria; IV. ÚLTIMAS REFLEXIONES... 


\title{
¿REGENERACIÓN DEMOCRÁTICA? ALGUNAS REFLEXIONES SOBRE LA NUEVA LEY ORGÁNICA 4/2013, DE 28 DE JUNIO, DE REFORMA DEL CONSEJO GENERAL DEL PODER JUDICIAL ${ }^{1}$
}

\author{
ROSA M. ${ }^{a}$ FERNÁNDEZ RIVEIRA \\ Profesora Contratada-doctora. Dpto. Derecho Constitucional \\ Universidad Complutense
}

\section{INTRODUCCIÓN}

Las páginas que se presentan a continuación pretenden reflexionar, de manera crítica, sobre las últimas reformas introducidas en el Consejo General del Poder Judicial. Supuestamente tales cambios se han ido fraguando en un marco de regeneración democrática ${ }^{2}$, algo de lo que no deja de hablarse en los últimos años y que resulta ser un concepto muy simple y complejo al mismo tiempo. Y ello tan sólo depende bien de la voluntad real de regenerar (cambiar, reformar, crear de nuevo)

${ }^{1}$ Este artículo se desarrolla dentro del DER2012-37921-C02-01. Titulado: Constitucionalización de la estabilidad presupuestaria y sus implicaciones en los procesos de presupuestación, ejecución y control del gasto público en una hacienda múltiple»; del Grupo de Investigación «970599 Equilibrio y Disciplina Presupuestaria (un horizonte de financiación de los servicios públicos).»

${ }^{2}$ Debate a la totalidad del proyecto de ley orgánica 4/2013, de reforma del CGPJ, Diario de Sesiones del Congreso de los Diputados, Pleno y Diputación Permanente, de 18 de abril de 2013: « [Ruiz Gallardón]...el debate que hoy celebramos tiene que ver, y mucho, con elementos absolutamente vitales para nuestra regeneración democrática, con elementos para la superación de la crisis de España, con elementos en los que tengamos la oportunidad de aportar el diálogo, la responsabilidad y la voluntad sincera de consolidar una arquitectura institucional sólida...», págs. 4 y ss. 
o, por el contrario, del uso demagógico y «políticamente correcto» que se viene haciendo de un concepto de gran potencial usado cual bálsamo de Fierabrás.

Un marco contextual, el de esta reforma, cargado también de debate político y doctrinal en torno a la conveniencia o no de un órgano de gobierno de jueces y magistrados como lo es (art. 122 de la CE) nuestro Consejo.

La Democracia necesita, entre otras cosas, que los partidos políticos funcionen democráticamente y que el Poder Judicial sea independiente ${ }^{3}$ tal como prescribe sin paliativos el artículo 117 de la CE. Dos grandes ideas protagonistas del debate, de difícil plasmación y mal cumplidas (o interiorizadas) en nuestro pasado y presente y, cuyos efectos ponen de relieve problemas que requieren solución. Evidentemente a todo ello no vamos a referirnos pues excedería con mucho el espacio y pretensión de estas líneas que son sólo otro peldaño en el debate sobre esta institución.

Robert B. Stevens señalaba que en Inglaterra la independencia judicial había sido una pieza básica de la retórica política ${ }^{4}$. Tal principio básico nunca se había

${ }^{3}$ La historia constitucional española no es precisamente una buena muestra de independencia judicial. Ya a principios del siglo XIX nos encontramos con documentos que avalan esta crítica. La Real Orden de 3 de octubre de 1835 del entonces Ministro de Justicia Gómez Becerra dirigida a todas las Audiencias señalaba: «...es absolutamente necesario...que todos los empleados además de reunir las siempre indispensables calidades de aptitud suficiente, de probidad nunca desmentida, de moralidad y reputación sin tacha, sean fieles y sinceramente adictos a la persona y legítimos derechos de nuestra Augusta e inocente reina la Sra. Dña. Isabel II ...»; Por su parte también, el Real Decreto de 6 de octubre de 1835 publicado en la Gaceta de 9 del mismo mes establecía: «Para que la Justicia se administre con rectitud, expedición y acierto que corresponde, es menester que los encargados de tan importante depósito tengan además de la probidad, pureza, fidelidad, buena fama, inteligencia y aplicación indispensables, la experiencia y práctica que sólo se adquieren con el manejo de los diferentes negocios forenses en sus diversas graduaciones...» en MORENO PASTOR, L., Los orígenes del Tribunal Supremo 1812-1838» Ministerio de Justicia 1989, pág. 230; ver también, Aparicio, M. A., El Status del Poder Judicial en el constitucionalismo español (18081936)», Universidad de Barcelona 1995;

4 «In England, judicial independence has been most important as a piece of political rhetoric. It is banded about in political disputes about legislation, such as those involving sentencing or judicial salaries. It is a term likely to be trotted out, both by government and opposition, when a new approach is offered for some criminal or civil remedy. Although it is never defined, it is always asserted. Lord Chancellors, who embody the judicial, executive, and legislative, often claim Britain does or does not have separation of powers depending on the context. The never deny that the judges are independent, as it is assumed that Locke, Hale, Montesquieu, and Blackstone settled this (...). It was Blackstone who gave a modern focus to the separation of powers, although his impact was far greater in North America than in Britain. I argue that there is a more or less accepted, although not always observed, theory of the independence of individual judges. Second, I argue that there is, at best, a confused notion of the independence of the judiciary as a branch of government, but not one that will withstand rational analysis. Third, I argue that the time may have arrived when there should be a clearer separation of powers, with something approaching an «independent» judiciary...» 
definido de manera estricta pero siempre se había respetado y cuidado. Es más, tras la reforma constitucional inglesa del año 2005 (Constitutional Reform Act 2005), el Lord Chancellor británico, salvaguarda institucional de la independencia judicial, sufría una profunda renovación y cambio. Ya no sería la cabeza del poder judicial, ya no sería la cabeza de la Cámara de los Lores, ya no se sentaría como juez en el Tribunal Supremo pero sí seguiría siendo garante de la independencia del poder judicial ${ }^{5}$. La búsqueda de la esencia de la independencia del poder judicial ha sido y es una constante.

Estas palabras escritas en 1998 y ávidas de un concepto claro de «independencia judicial» podríamos suscribirlas hoy y utilizarlas como reflexión de cabecera para analizar el nuevo Consejo General del Poder Judicial, garante de la independencia de la justicia, en general, y de la independencia de cada juez, en particular.

¿Cómo garantizar la independencia judicial?, ¿qué modelo de órgano de gobierno de jueces y magistrados debe adoptarse?, siguen siendo eternas preocupaciones. $^{6}$

La reforma que estudiamos apenas tiene recorrido pero las críticas que ha recogido hasta el momento, no son demasiado positivas. Todas las asociaciones judiciales, la mayoría de la doctrina y de las fuerzas políticas ven con recelo este nuevo Consejo ${ }^{7}$.

en Stevens Robert B., «The independence of the Judiciary: the case of England», Southern California Law Review, 72, 1998, págs. 597 y ss.

5 «The Lord Chancellor is required to take an oath in which the office holder undertakes to respect the rule of law, defend the independence of the judiciary and ensure the provision of resources for the efficient and effective support of the courts... In the past, a vitally important part of the Lord Chancellor's role was to protect the judiciary from the undeserved and unsubstantiated criticisms of the press, the public, and his ministerial colleagues alike. Now, there is also a guarantee of continued judicial impendence to be found in art. 3.1 of the 2005 Act which provides: «...The Lord Chancellor, other Ministers of the Crown and all with responsibility for matters relating of judiciary or otherwise to the administration of justice must uphold the continued independence of the judiciary...» en Neil Parpworth, Constitutional Administrative Law, Oxford University Press 2012, págs.22-23.

${ }^{6}$ El informe suscrito por el Consejo consultivo de Jueces de Europa en 2007 sobre Consejos de Justicia ofrece alguna idea al respecto: «...el Consejo de Justicia debe establecer las herramientas necesarias para la evaluación de la justicia, rendir cuentas del estado de los servicios y pedir a las autoridades competentes que tomen las medidas necesarias para mejorar la administración de justicia. El CCJE recomienda que el Consejo de Justicia sea, al menos en los países dotados de una Constitución escrita, especificado en ésta o, al menos, en el instrumento legislativo o constitucional equivalente [....]», Informe N. ${ }^{\circ} 10$ (2007) del Consejo consultivo de Jueces Europeos (CCJE) a la atención el Comité de Ministros del Consejo de Europa sobre el Consejo de la Justicia al servicio de la sociedad, Estrasburgo, 21-23 noviembre 2007.

7 Debate a la totalidad al proyecto de ley orgánica 4/2013, de reforma del CGPJ, Diario de Sesiones del Congreso de los Diputados, Pleno y Diputación Permanente, de 18 de abril de 2013: «... 
Este es el marco de análisis y antes de pasar al estudio pormenorizado de los cambios que introduce la nueva ley añadiremos que el 5 de noviembre de 2013 el TC ha admitido un Recurso de Inconstitucionalidad interpuesto por el Grupo Parlamentario Socialista contra diversos artículos de aquélla. Así las cosas habrá que esperar, observando atentamente su andadura, a obtener el fallo de nuestro máximo intérprete.

\section{LA NUEVA LEY ORGÁNICA 4/2013, DE 28 DE JUNIO, DE REFORMA DEL CONSEJO GENERAL DEL PODER JUDICIAL: CONTEXTO Y GESTACIÓN DE LA REFORMA.}

El 28 de junio de 2013 se aprueba la reforma de la Ley Orgánica 6/1985, de 1 de julio, del Poder Judicial por la que se reforma el Consejo General del Poder Judicial (BOE, sábado 29 de junio de 2013).

El marco normativo de la misma es obviamente el artículo 122 de la CE que expone los ejes estructurales de este órgano constitucional. El último párrafo del

[Baldoví Roda] Señor Ministro, tengo que reconocerle un gran mérito. En apenas año y medio ha conseguido usted una clamorosa unanimidad: tener a todos en su contra. No es fácil, pero usted lo está consiguiendo. Hoy cinco grupos de esta Cámara defienden una enmienda a la totalidad de la ley de reforma del Consejo General del Poder Judicial y su devolución. Están en contra la mayoría de asociaciones profesionales de la justicia, la mayoría de miembros del Consejo General del Poder Judicial, incluso ha conseguido que hubiera una huelga en contra de sus decisiones — por cierto, una huelga con un seguimiento francamente mayoritario- . Por eso, he intentado ver esta reforma como la vería un ciudadano corriente y hay una cosa, a pesar de toda su intervención, que salta de inmediato a la vista. En un tema de tanta trascendencia cuando estamos hablando de la independencia de uno de los pilares fundamentales del Estado usted nos presenta una reforma que no cuenta, que no ha concitado ningún consenso y que pretende aprobar únicamente con su mayoría absoluta. Con todo esto, se lo pregunto francamente, ¿qué mensaje está mandando usted a los ciudadanos, señor ministro? Si la mayoría de grupos de esta Cámara estamos en contra, ¿qué pasará si dentro de dos años y medio ustedes pierden su mayoría absoluta? ¿Tendremos que abordar una nueva reforma?...», pág. 10; El informe del Consejo de Europa elaborado por GRECO (Group of States against Corruption) y publicado el 15 de enero de 2014, critica el nuevo sistema de elección de los vocales que cede al Parlamento la totalidad del protagonismo entendiendo que si bien razones históricas pudieron justificar que fuera el Parlamento el garante de la independencia judicial, en la actualidad tanto la teoría como la práctica demuestran que son los propios jueces quienes mejor pueden autolimitarse y garantizar la salvaguarda de la misma.

«...The GET further notes that the establishment of judicial councils is generally aimed at better safeguarding the independence of the judiciary - in appearance and in practice, the result in Spain seeming to be the opposite as evidenced by recurrent public disquiet in this domain. This is particularly dangerous at a time when cases involving political corruption are on the rise...»FOURTH EVALUATION ROUND, Corruption prevention in respect of members of Parliament, Judges and Prosecutors, Spain, Strasbourg, 2-6 December 2013, págs. 24 y so; http://www.coe.int/t/dghl/ monitoring/greco/evaluations/round4/GrecoEval4(2013)5_Spain_EN.pdf 
preámbulo de la nueva ley orgánica de reforma del Consejo General del Poder Judicial, (en adelante LOPJ) dice: «...Actualmente, el Consejo General del Poder Judicial demanda una reforma en profundidad de su estructura y funcionamiento que permita poner fin a los problemas que a lo largo de años se han puesto de manifiesto, así como dotarlo de una estructura más eficiente.»

El CGPJ experimenta, con la reforma de 2013 que analizamos en estas líneas, su cuarto modelo o planteamiento. El primero de ellos se recoge en la ley orgánica 1/1980, de 10 de enero («...del Consejo General del Poder Judicial»), el segundo, articulado en la ley orgánica 6/1985, de 1 de julio del Poder Judicial y tildado como el «de elección parlamentaria o predominio de los partidos» ${ }^{8}$; y el tercero regulado en la ley orgánica $2 / 2001$, de 28 de junio, que introduce elementos corporativos nuevos pero sin abandonar una elección de sus miembros predominantemente parlamentaria.

El modelo vigente surge en un marco de profundo descrédito respecto a la institución que se ve permanentemente sometida a duras críticas (ciertamente merecidas) por parte de todas las asociaciones judiciales y la opinión pública. Un contexto además, adornado de escandalosas prórrogas y dimisiones como la presentada en junio de 2012 por el entonces presidente Carlos Dívar.

En tales términos el Ministro de Justicia Alberto Ruiz-Gallardón encarga a una comisión de expertos la reforma del órgano de gobierno de jueces y magistrados. Los principales asuntos a tratar serán: el eterno debate sobre la designación de los vocales del Consejo y la interpretación al respecto del 122.3 CE, la eficiencia y austeridad económica en su funcionamiento, el ámbito y concreción de sus potestades y atribuciones, su procedimiento de renovación y la efectiva protección de la independencia judicial.

El proyecto de ley se presenta en el Congreso de los Diputados el 1 de marzo de 2013 y tras agotar la tramitación parlamentaria se vota en sesión plenaria de 27 de junio, obteniendo 183 votos a favor, 140 en contra y una abstención.

De su andadura parlamentaria y aspectos formales merecen ser reseñados algunos elementos:

\section{a) El «sudoku» de la entrada en vigor}

La disposición final tercera de la LOPJ establece tres tipos de vigencia en los contenidos de la misma. En primer lugar, la ley entrará en vigor el día siguiente de su publicación sólo para lo relativo a la renovación, designación y elección

8 IÑiguez HernándeZ, D., El fracaso del autogobierno judicial, Thomson/Civitas, 2008, pág.221; 
de los vocales del CGPJ, así como para la constitución del mismo. Por otra parte, el resto de contenidos de la LOPJ entrará en vigor el día en que se constituya el primer CGPJ conforme a lo dispuesto en esta ley. Y, por último, los Reglamentos aprobados por el CGPJ conservarán su vigencia, «en tanto sean compatibles con la presente ley orgánica» generando por tanto una suerte de incertidumbre de vigencia.

\section{b) Flecos normativos resueltos con una ley orgánica de artículo único}

El viernes 12 de abril de 2013, en plena tramitación del proyecto de ley orgánica de reforma del CGPJ, se publica en el BOE la ley orgánica 1/2013, de 11 de abril sobre el proceso de renovación del Consejo General del Poder Judicial, por la que se suspende la vigencia de los artículos 112 y parcialmente del 114 de la ley orgánica 6/1985, de 1 de julio, del Poder Judicial. Esta ley orgánica integrada sólo por un artículo y una Disposición final, suspendía la vigencia de los referidos artículos que establecían el procedimiento de selección de los vocales del Consejo de entre jueces y magistrados.

Su Exposición de Motivos reconocía: «...La entrada en vigor de un nuevo sistema de elección de los Vocales del CGPJ en fechas cercanas a su renovación no es un hecho ignoto en la historia del Consejo General del Poder Judicial...»

Y siendo eso cierto, la diferencia con el caso anterior fue la distinta forma en que se resolvió, esto es, la publicación entonces de la Instrucción de 29 de junio de 2001 del Presidente del CGPJ determinando el número de candidatos a presentar por las Asociaciones profesionales de jueces y magistrados y concretando a su vez, otros aspectos del proceso de formulación de las candidaturas.

Resulta chocante ahora el uso de una Ley orgánica de artículo único. Y en este sentido compartimos la crítica de la indefinición del ámbito material de las leyes orgánicas de Santamaría Pastor (1988), que sistematizando el contenido de aquéllas aludía a una categoría material «cajón de sastre»: ley orgánica singular o de autorización ${ }^{9}$ y criticaba entonces la «arbitrariedad del constituyente» en la delimitación de las leyes orgánicas. Ahora bien, de manera constructiva y con ciertas

9 «Leyes orgánicas singulares o de autorización, que comprenden un cajón de sastre de supuestos específicos e inconexos entre sí, como la resolución de dudas en el orden de sucesión a la Corona (art. 57.5CE), la autorización de tratados por los que se transfiera a una organización internacional competencias derivadas de la CE (art. $93 \mathrm{CE}$ ), la modificación de los límites provinciales (art. 141.2 CE), la autorización para constituir una Comunidad autónoma de ámbito territorial no superior a una provincia y que no reúna las condiciones del art. 143.1 CE (art. 144 a), la autorización para otorgar Estatuto de Autonomía a territorios no integrados en la organización provincial (art. 144 b) y la sustitución de la iniciativa de las Corporaciones locales en orden a la 
dosis de comprensión explicaba: «...la Constitución es un texto político, no un trabajo académico, y sus parámetros de coherencia son completamente distintos de los productos intelectuales: la abundancia y asimetría del conjunto de materias confiadas a la ley orgánica fueron, quizá, una parte del precio que hubo que pagar para que la elaboración de la Constitución llegara a feliz término...»

A la luz de estas reflexiones y viendo cómo el legislador ha resuelto un problema de «transición legislativa» con una ley orgánica de artículo único, nos preguntamos si la comprensión de las peculiaridades del «proceso constituyente» puede seguir siendo operativa en el año 2013 o si, por el contrario, nuestra técnica legislativa y nuestro sistema de fuentes, a principios del siglo XxI y con 35 años de vigencia de la Constitución de 1978, siguen demandando un concepto material de ley orgánica.

c) El «corta de aquí y pega allá»

La LOPJ está compuesta de un nuevo Libro VIII que se desarrolla por los artículos 558 a 642, (seis Títulos), dos Disposiciones Adicionales, diez Disposiciones Transitorias, una Disposición Derogatoria y tres Disposiciones Finales.

En el anterior Texto normativo se destinaba a regular el Consejo el libro II: «Del Gobierno del Poder Judicial», (arts. 104-148), preceptos que han quedado derogados; ahora el Texto vigente deja un enorme hueco, tanto de fondo como de forma, en el articulado.

Sobre la reciente reforma que estudiamos apenas hay trabajos doctrinales, por el contrario contamos con documentos de relevancia que la analizan como es el que, en cumplimiento del artículo 108 de la LOPJ, nos brinda el Pleno del Consejo.

El informe del Pleno del CGPJ ${ }^{10}$ señalaba sobre la técnica normativa elegida: «... se rompe la sistemática de la LOPJ[...] Con la regulación que ahora se pretende introducir, llevando lo que hoy constituye el Título II, del Libro II, a un nuevo Libro VIII, a la par que se deja un hueco en el articulado de la ley, se rompe la sistemática de la LOPJ, ya que se mantiene el Libro II, con su rúbrica general relativa al gobierno del Poder Judicial [...] esta regulación íntegra ex novo del CGPJ,... sin que se modifiquen en paralelo otros numerosos preceptos de la propia ley, que incluyen citas o referencias a competencias o intervención del

constitución de una Comunidad Autónoma (art. 144.2 CE)...» en SAntamaría Pastor, J. A., Fundamentos de Derecho Administrativo I, Ramón Areces, Madrid 1988, pág. 567.

${ }^{10}$ Con fecha de 8 de enero de 2013 el Pleno del CGPJ de acuerdo a lo establecido en el artículo 108 de la LOPJ elabora un Informe al anteproyecto de ley orgánica de reforma del CGPJ. 
propio Consejo, introduce un serio grado de confusión normativa, ajeno a la claridad deseable de las leyes, hasta tal punto que al menos tres disposiciones transitorias hacen referencia, directa o indirecta, a la necesidad de reformas legislativas posteriores de la LOPJ para adaptarla a esta reforma [...]»

Nuestra más autorizada doctrina en Técnica legislativa reflexiona señalando que: «la estructura o sistematización de la ley hace referencia a su ordenación interna, la cual, además de venir determinada por criterios de orden lógico, tiene como finalidad facilitar la localización de cada precepto en el conjunto del texto normativo [...] una estructura adecuada y uniforme ayuda a superar las dificultades de localización y produce además un efecto directo positivo de comprensibilidad e interpretación.» ${ }^{11}$

\section{CONTENIDO DE LA REFORMA}

Analizamos ahora las principales modificaciones que introduce la nueva ley que sin duda son de profundo calado, lo que comparten, entre otros, Pérez Minaya J. y así de manera gráfica opina que se ha matado al Consejo General del Poder Judicial tal como lo conocíamos y sólo nos quedan sus restos. Procede por ello hacer una autopsia que será breve, pues la causa de la muerte está muy clara: la voluntad de la clase política de controlar al Poder Judicial ${ }^{12}$.

11 García-Escudero Márquez, P., Manual de Técnica Legislativa, Civitas 2011, págs. 97-98

12 Pérez Minaya, J., publicaba el artículo: «Crónica de una muerte anunciada. Breve autopsia del Consejo General del Poder Judicial», en Diario La Ley, N. ${ }^{\circ}$ 8126, Sección en Primera Persona, 15 Jul. 2013, Año XXXIV, Editorial La Ley, «...Que la politización ha sido el pecado capital de los sucesivos Consejos del Poder Judicial apenas puede discutirse. Elegidos por las Cortes Generales, los integrantes de nuestro órgano de gobierno han venido en no pocas ocasiones a reproducir, en pequeña escala, el equilibrio de fuerzas existentes en el mismo parlamento. [...] La LO 4/2013 alumbra un nuevo órgano de gobierno del Poder Judicial compuesto por cinco vocales: los integrantes de la Comisión Permanente... nos encontramos ante un fenómeno de concentración del poder en una parte, que, además se encuentra jurídicamente aislada e independiente del todo. ¿Alguien se imagina que el Secretario de Justicia pudiera adoptar decisiones sin facultad de control y revisión por el Sr. Ministro de Justicia? El Pleno del Consejo no tiene facultad legal de revisar y dejar sin efecto acuerdos de la Permanente...»; ver también Dolado Pérez, A., «Valoración del Nuevo Consejo General del Poder Judicial» ibídem; CoBo SÁENZ ,J. F., «La reforma de la estructura organización y funciones del Consejo General del Poder Judicial por ley orgánica 4/2013 y el acervo del Consejo de Europa sobre Consejos de la Justicia» ibidem; Pleite Guadamillas, F., «El desapoderamiento competencial del Consejo General del Poder Judicial, ibídem; Benacloche Palao, J., «La insólita reforma de la organización y funcionamiento del Consejo General del Poder Judicial», ibídem. 
En una línea parecida, el magistrado Perfecto Andrés entiende también que es muy ambiciosa la reforma: «El Consejo General del Poder Judicial vuelve a quirófano» ${ }^{13}$. No estamos por tanto ante una coyuntural o secundaria modificación, la reforma que analizamos redimensiona de manera plena este órgano constitucional.

El análisis que exponemos reproduce la sistematización de los principales cambios que el legislador de la reforma ha utilizado en su Exposición de Motivos. Ordenar los problemas de esta ley 4/2013, reflexionar jurídicamente en voz alta y sugerir que no se camina por la senda de la regeneración democrática, son los pilares de las siguientes líneas.

\section{Atribuciones del Consejo}

Se reducen las competencias del Consejo que se trasladan al Gobierno. Se concentran las competencias del Consejo en su Presidente y su Comisión Permanente. Se preguntaba el magistrado Íñiguez Hernández, ¿son necesarias todas las funciones que ha desarrollado el Consejo desde la ampliación de sus competencias en 1994, para su función constitucional? Posiblemente no, aunque es necesario entender el autogobierno con una cierta amplitud, para evitar que quede reducido a las labores de un negociado de personal... ${ }^{14}$.

Resulta ciertamente provocador (excusatio non petita acusatio manifesta...) el comienzo en la Exposición de Motivos de nuestro legislador del Consejo vigente: «... Las atribuciones del Consejo no se ven sustancialmente alteradas. Se prevé simplemente que las que tenga legalmente reconocidas sean acordes con la finalidad que justifica la existencia misma del CGPJ a saber: sustraer al Gobierno la gestión de las diversas vicisitudes de la carrera de jueces y magistrados, de manera que no pueda condicionar su independencia por esta vía indirecta...».

En la Exposición de motivos se refieren tres importantes cambios de atribuciones del Consejo:

- La actividad internacional del Consejo General del Poder Judicial

En primer lugar, toda la actividad internacional (o aquellas atribuciones constitucionales y legales que puedan tener de algún modo proyección interna-

13 Andrés IbaÑez, P., «El Consejo General del Poder Judicial vuelve a quirófano» en Jueces para la Democracia, n. ${ }^{\circ} 73,2012$, págs. 12-20;

${ }^{14}$ IÑIguEZ HernáNDEZ, D., «El autogobierno judicial, hacia una nueva edad de hielo» en Revista del Poder Judicial n. ${ }^{\circ}$ 95, 2013 pág. 29. Con gran acierto, a nuestro juicio, Iñiguez Hernández señala: «...La cuestión del gobierno judicial es un problema no de organización o de eficacia de la jurisdicción. Se refiere al modo en que se articulan, compiten o se ordenan entre sí, los actores de la política judicial, ...» 
cional) del Consejo deberán estar coordinadas con el Ministerio de Asuntos Exteriores y de Cooperación. Lo que significa claramente que se reconduce esta materia al marco del artículo 97 de la CE que atribuye al ejecutivo la titularidad en la dirección de la política exterior. Y todo ello sin perjuicio, dice el artículo 562 de la LOPJ, de las «competencias que en materia de «cooperación jurisdiccional internacional» ostenta el Consejo General del Poder Judicial». ${ }^{15}$

- La elaboración y ejecución del presupuesto del CGPJ.

En segundo lugar, se reconoce (art. 565) que el CGPJ como órgano constitucional autónomo debe elaborar y ejecutar su propio presupuesto, tarea sujeta en todo caso a la legislación presupuestaria general. Se recuerda también la vinculación del Consejo en el desarrollo de esta competencia presupuestaria a los principios de estabilidad y sostenibilidad (LO 2/2012, de 27 de abril de estabilidad presupuestaria y sostenibilidad financiera). Y se detallan los mecanismos de control interno y externo del gasto del CGPJ. Aquél, se llevará a cabo por un funcionario del cuerpo superior de Interventores y Auditores del Estado, pero que dependerá funcionalmente del Consejo y, éste (esto es el control presupuestario externo), se llevará a cabo por el Tribunal de Cuentas.

- La potestad reglamentaria.

Pero el cambio más relevante en materia competencial lo protagoniza sin duda la potestad reglamentaria del Consejo que queda reducida a la esfera puramente interna o doméstica y tan sólo excepcionalmente y para determinados aspectos accesorios de las actuaciones judiciales previstas por la LOPJ se admitirá una potestad reglamentaria ad extra.

El artículo 560.1.16..$^{\circ}$ establece: «El Consejo General del Poder Judicial tiene las siguientes atribuciones: ...ejercer la potestad reglamentaria en el marco estricto de desarrollo de las previsiones de la ley orgánica del poder judicial...»; a su vez, esta facultad se restringe a un listado determinado de materias detalladas en la propia ley (lo que también hacía el texto anterior), por ejemplo: a) la organización y funcionamiento del CGPJ, b) el personal del Consejo en el mar-

15 Pulido Quecedo, M.: «...su actividad internacional, la denominada «diplomacia judicial» con viajes gratis total, se ve recortada y reconducida, y así debe ser proyectada y ejecutada en coordinación con el Gobierno y el Ministerio de AAEE» en: «El nuevo Consejo General del Poder Judicial» en Diario La Ley, n. . 8126, 2013; 
co de la legislación sobre la función pública, c) órganos de gobierno de Juzgados y Tribunales...; i) reparto de asuntos y ponencias, etc.

Ahora bien, a lo ya descrito, se añaden límites que abundan en la reducción del contenido de la potestad reglamentaria, por ejemplo: el apartado $\mathrm{m}$ ) permite la regulación reglamentaria sobre condiciones accesorias para el ejercicio de derechos y deberes del estatuto de jueces y magistrados y para lo relativo al régimen jurídico de las Asociaciones judiciales pero: «... sin que tal desarrollo reglamentario pueda suponer innovación o alteración alguna de la regulación legal» (la antigua ley hablaba de alteración «en su conjunto») ${ }^{16}$. Esta redacción elimina todo tipo de cambio.

Y por último, constriñendo aún más si cabe la potestad: se prohíbe que en ningún caso las disposiciones reglamentarias del CGPJ puedan afectar o regular directa o indirectamente derechos o deberes de personas ajenas al Consejo.

\section{- Evolución y desarrollo de la potestad reglamentaria del CGPJ ${ }^{17}$}

La potestad reglamentaria del Consejo fue siempre una cuestión debatida. El artículo 5 de la primera Ley del Consejo de 1980 establecía: «El Consejo General del Poder Judicial podrá dictar reglamentos sobre su organización y funcionamiento, así como sobre el régimen del personal y servicios y demás materias de su competencia dentro del ámbito de la presente Ley...»; poco tiempo después y en similares términos se expresaba el art. 110 LOPJ de 1985.

Pero la delimitación del ámbito de la potestad reglamentaria seguiría siendo un asunto controvertido y en 1986 el TC se pronuncia mediante STC 108/1986, de 29 de julio que analizaba no sólo el reparto de la potestad reglamentaria entre el Consejo y el ejecutivo en materia de organización y funcionamiento del status de jueces y magistrados, sino también los contenidos materiales de la misma. La

16 Resulta útil comparar la distinta redacción sobre potestad reglamentaria (sobre todo por los términos usados en la ley vigente: «... en el marco estricto de...», «sin innovación o alteración alguna de...», «en ningún caso [...] podrán afectar o regular directa o indirectamente...) del artículo 110.2 párrafo segundo de la antigua LOPJ: «...Estos reglamentos podrán regular condiciones accesorias para el ejercicio de los derechos y deberes que conforman el estatuto judicial sin innovar aquellos ni alterar éste en su conjunto. Podrán aprobarse en los casos en que sean necesarios para la ejecución o aplicación de esta ley, en aquellos en que así se prevea en esta u otra ley y, especialmente, en las siguientes materias: ...»

17 Gerpe landín, M. y Barceló I Serramalera, M., «La potestad reglamentaria de desarrollo de la Ley orgánica del Poder Judicial», en Revista Jurídica de Catalunya, n. ${ }^{\circ}$ 1, 2003, págs. 132 y 133 . 
respuesta del máximo intérprete constitucional fue sobretodo de aproximaciones y muy laxa:

1. La reserva de ley orgánica no excluye la posibilidad de desarrollos reglamentarios (art. 122.1 CE). Esto es, el status de jueces y magistrados, su conjunto de derechos y deberes ha de venir determinado por ley orgánica, pero ello no es obstáculo para que, regulaciones de carácter secundario y auxiliar puedan ser reguladas por vía reglamentaria de manos por tanto del Consejo.

2. Tal aceptación e interpretación «amplia» de la potestad reglamentaria del CGPJ constituye una garantía de las funciones que la LOPJ asigna al Consejo en aras de garantizar la independencia judicial.

3. También será posible, en determinados casos, que la potestad reglamentaria corresponda al Gobierno, siempre dentro de los límites exigidos por la Constitución y la propia LOPJ. El gobierno sólo estará habilitado para dictar reglamentos que no innoven derechos y deberes integrantes del estatuto de jueces y magistrados.

Por lo tanto, señalar a priori cuándo correspondería al Gobierno o, cuándo al Consejo, resultaba innecesario porque los problemas se resolverían desde otra perspectiva y así, en caso de uso indebido de la misma «existían cauces legales» para resolverlos. Bacigalupo Saggese entendía: «...el Tribunal satisfizo tan sólo parcialmente la pretensión de los recurrentes [...], no llegó a declarar con meridiana claridad que dicha potestad se hallaba constitucionalmente reservada en exclusiva al CGPJ, al entender, por el contrario, que se trataba de una potestad compartida o concurrente con la del gobierno...» ${ }^{18}$

Con la ley orgánica 16/1994, de 8 de noviembre se incorporaba un nuevo apartado relativo a la potestad reglamentaria ad extra ${ }^{19}$. Gerpe Landín y Barceló

18 Bacigalupo Saggese, M., «La potestad reglamentaria del Consejo General del Poder Judicial», en Derecho Privado y Constitución, n. ${ }^{\circ}$ 17, Enero-diciembre 2003, pág. 24; Ver también: Navas Sánchez, M.., Poder Judicial y sistema de fuentes: la potestad normativa del Consejo General del Poder Judicial, Civitas, 2002; Porras Ramírez, J. M., «Fundamento, naturaleza, extensión y límites de la potestad reglamentaria del Consejo General del Poder Judicial (a propósito de la nueva regulación introducida por la LO 16/1994, de 8 de noviembre por la que se reforma la LO 6/1985, del Poder Judicial) en Revista de Estudios Políticos, n. 87, 1995; FernándeZ-Miranda, J., «La potestad reglamentaria del Consejo General del Poder Judicial» en Revista de Administración Pública 189, septiembre-diciembre 2012;

19 Art. 110.2. LOPJ: «...2. El Consejo General del Poder Judicial, en el ámbito de su competencia y con subordinación a las leyes, podrá dictar Reglamentos de desarrollo de esta Ley para establecer regulaciones de carácter secundario y auxiliar. Estos Reglamentos podrán regular condiciones accesorias para el ejercicio de los derechos y deberes que conforman el estatuto judicial 
i Serramalera analizaban esta potestad ad extra del Consejo y su fundamentación material valorando positivamente la reforma del año 1994: «...la potestad reglamentaria ad extra que legislativamente se atribuye al Consejo, tiene un carácter derivado de modo que sólo excepcionalmente y en la medida que la materia a regular se encuentre en el ámbito de su función constitucionalmente encomendada, podrá desplegar (el CGPJ) el ejercicio de dicha potestad. Esos otros ámbitos referidos a regulaciones que no sirvan para impedir una injerencia del Gobierno en la independencia de jueces y magistrados escapan a cualquier posible regulación constitucionalmente legítima por parte del Consejo y corresponden al Ejecutivo como titular originario de la potestad reglamentaria...» ${ }^{20}$ Por lo tanto se configuraría una potestad reglamentaria ad extra excepcional y no expansiva.

Las modificaciones legislativas sucesivas han ido en la misma dirección: la ley orgánica 19/2003, de 23 de diciembre no sólo mantenía la potestad reglamentaria (ad intra y extra) ya reconocida sino incluso la ampliaba.

Con la nueva reforma se produce un importante «desapoderamiento competencial» sobre todo en la potestad reglamentaria ad extra.

¿Qué va a pasar a partir de ahora con el nuevo texto normativo? ¿Qué criterios van a decidir la aplicación de los reglamentos existentes? ¿Y la potestad para elaborar nuevos? No podemos decir que la Disposición Adicional primera lo haya puesto nada fácil: «Los actuales reglamentos aprobados por el Consejo General del Poder Judicial conservarán su vigencia, en tanto sean compatibles con la presente ley orgánica».

Una última cuestión competencial se plantea en el artículo 564 de la ley orgánica 4/2013 con motivo de las comparecencias: «Fuera del supuesto del artículo anterior $^{21}$ sobre el Presidente del Tribunal Supremo y los Vocales del CGPJ no recaerá deber alguno de comparecer ante las Cámaras por razón de sus funciones».

Caben algunas reflexiones al respecto, sin perjuicio de que este cambio requiera un tratamiento monográfico que sin duda trasciende a estas líneas. Y

sin innovar aquéllos ni alterar éste en su conjunto. Podrán aprobarse en los casos en que sean necesarios para la ejecución o aplicación de esta Ley, en aquéllos en que así se prevea en esta u otra Ley y, especialmente, en las siguientes materias:...»

20 Gerpe Landín, M. y Barceló I Serramalera, M., «La potestad reglamentaria de desarrollo de la Ley orgánica del Poder Judicial», en Revista Jurídica de Catalunya, n. . 1, 2003, págs. 136 y ss.

${ }^{21}$ El artículo 563 se refiere a la Memoria anual que el CGPJ tendrá que presentar a las Cortes Generales en ella se detallará lo propio sobre estado, funcionamiento y actividades del Consejo y de los Juzgados y Tribunales, así como sobre las necesidades en materia de personal, instalaciones y recursos para el correcto funcionamiento de las funciones asignadas por el Constituyente y legislador al poder judicial. Tal memoria se debatirá y podrá dar lugar a la petición de comparecencia del Presidente del TS para responder a preguntas sobre la misma. 
ello si se contemplan las numerosas comparecencias que tanto el Presidente del Consejo como sus vocales han protagonizado ante las Cámaras ${ }^{22}$ a lo largo de todas las legislaturas.

Si el artículo $44.4 .^{\circ}$ de nuestro Reglamento del Congreso entiende que es potestad de la comisión «la comparecencia de personas competentes por razón de la materia objeto del debate, a fin de informar a la Comisión», y, a su vez, el artículo 72.1 de la CE concede autonomía normativa (reglamentaria) a las Cámaras limitando la reforma de éstos. Podríamos entender que este precepto de la nueva ley orgánica 4/2013 estaría mermando la competencia de las cámaras y reformando a su vez, implícitamente, el Texto del reglamento parlamentario.

Del Pino Carazo se refiere a las comparecencias como las «cenicientas» en el tratamiento doctrinal respecto de otros mecanismos de control parlamentario (comisiones de investigación, interpelaciones, preguntas, etc.) ${ }^{23}$ pero al mismo tiempo dotadas de una intrínseca fortaleza que permite, no tanto acceder a información desconocida, que resulta poco probable que así sea, sino más bien someter a juicio crítico y a confrontación de posiciones determinados comportamientos o actos institucionales.

Si recordamos el texto anterior de la LOPJ, su art. 109.2 y 3 permitía la solicitud de comparecencias por parte de las Cámaras tanto al Presidente como a sus vocales. Tales comparecencias podrían dar lugar a mociones, preguntas de obligada contestación o cuantas medidas considerasen los propios Reglamentos parlamentarios.

${ }^{22}$ Son muchísimos los ejemplos que se pueden citar, algunos de ellos: comparecencia del Presidente del CGPJ ante la Comisión de Justicia e Interior para informar sobre determinados extremos y actuaciones del vocal Gómez de Liaño (V Legislatura, expediente 212/458); comparecencia del Presidente del Consejo ante la comisión constitucional para informar sobre ciertos contenidos de las Proposiciones de ley orgánica reguladoras de la cláusula de conciencia de periodistas y de secreto profesional (V Legislatura expediente 212/676); comparecencia del Presidente del Consejo para explicar y aclarar extremos relacionados con la excarcelación de presos preventivos a la espera de juicio en la Audiencia Nacional por delitos de terrorismo y narcotráfico (V Legislatura expediente 212/1774); comparecencia del Presidente del Consejo para informar acerca de investigaciones relacionadas con la sustracción de sumarios en los Juzgados de Marbella (VII Legislatura expediente 212/869); comparecencia del Presidente del Consejo para informar acerca de las repetidas declaraciones del Consejo contra el Proyecto de Ley de Estatuto de Autonomía de Cataluña (VIII Legislatura expediente 212/977), también hay muchos ejemplos de inadmisión de la Mesa de la Cámara de determinadas comparecencias, por ejemplo, la inadmisión de la comparecencia para informar por el Presidente del Consejo sobre el indulto concedido a Javier Gómez de Liaño (VII Legislatura expediente 212/331), inadmisión que dio origen a la STC 40/2003

${ }^{23}$ Del Pino Carazo, A., «Comparecencias ante las Comisiones de la Asamblea de Madrid», Revista Parlamentaria de la Asamblea de Madrid, n. ${ }^{\circ}$ 2, diciembre 1999, págs. 162 y ss. 
¿Qué motivos han llevado al legislador a suprimirlas? Este cambio se separa sustancialmente del anterior artículo 109.2 de la ley orgánica del Poder Judi$\mathrm{cial}^{24}$, se aleja de la jurisprudencia del TC sobre «comparecencias» ${ }^{25}$ y lo que es aún peor, se sitúa en las antípodas de la demanda social de responsabilidad política, transparencia y regeneración democrática.

La actividad parlamentaria española está plagada de ejemplos en los que se ha solicitado y llevado a cabo la comparecencia del Presidente del CGPJ ante las comisiones de las Cámaras. La STC 191/2013, de 18 de noviembre, señala que cuando las «comparecencias» aparecen previstas en el Reglamento de la Cámara, se integran en el ius in officium del representante y, además en cuanto su finalidad sea el control del Gobierno, han de entenderse incluidas dentro del núcleo básico de la función parlamentaria, garantizado por el artículo $23.2 \mathrm{CE} »^{26}$.

${ }^{24}$ Art. 109. 2.: «...debatir el contenido de dicha memoria y reclamar, en su caso, la comparecencia del Presidente del Consejo General del Poder Judicial o del miembro del mismo en quien aquél delegue. [...]»

25 STC 208/2003, de 1 de diciembre, BOE, 8 de enero de 2004, págs. 27-37, en esta sentencia el Tribunal otorgó el amparo solicitado por diversos parlamentarios del grupo socialista que entendían vulnerado su derecho fundamental (ius in officium) ex art. 23.2 por el acuerdo de la Mesa denegando la comparecencia del entonces presidente del CGPJ ante la Comisión de Justicia e Interior para informar sobre la posición del Consejo ante el indulto de Javier Gómez de Liaño, en los términos en que había sido concedido por el Gobierno. Recuerda el Tribunal que son las comparecencias herramientas integrantes del derecho fundamental de los ciudadanos a participar en los asuntos públicos (art. 23.1CE) y así dice además en los Fundamentos Jurídicos 4 y 5: «...a la Mesa sólo le compete, en principio por estar sujeta al ordenamiento jurídico, en particular a la Constitución y a los Reglamentos parlamentarios, y en aras de la mencionada eficacia del trabajo parlamentario, verificar la regularidad jurídica y la viabilidad procesal de la iniciativa... que excluye cualquier tipo de juicio de oportunidad...»

26 STC 191/2013, de 18 de noviembre, por la que se interpuso recurso de amparo por la Síndic (Portavoz) del Grupo parlamentario de Esquerra Unida, Dña. Rosario Margarita Sanz Alonso del Parlamento Valenciano: «...este recurso de amparo parlamentario tiene especial trascendencia constitucional al verse afectado, (...) una manifestación del derecho de representación política (art. 23.2 CE) como es el control de la acción del gobierno a través de solicitudes de comparecencias parlamentarias cuyo contenido precisa ser perfilado.»El artículo 44 del Reglamento del Congreso de los Diputados establece: «Las Comisiones por conducto de su Presidente del Congreso podrán recabar: ...4..$^{\circ}$ La comparecencia de otras personas competentes en la materia (se entiende por tanto que distintas que los miembros del Gobierno y de las autoridades y funcionarios públicos competentes que se contemplan en apartados anteriores) a efectos de informar y asesorar a la Comisión.» El artículo 67 del Reglamento del Senado dice: «...Las Comisiones [...] podrán recabar, a través del Presidente del Senado, la información y ayuda que necesiten del Gobierno y de sus Departamentos y de cualesquiera autoridades del Estado (la cursiva es nuestra) y de las Comunidades Autónomas, [...] Asimismo podrán solicitar la presencia de otras personas para ser informadas sobre cuestiones de su competencia.» 
El Tribunal es consciente de que el contenido y alcance de la comparecencia como herramienta de control debe ser perfilado en su contenido. Y aprovecha esta ocasión para hacerlo en su contenido objetivo, pero no despeja el alcance o dimensión subjetiva de los sujetos destinatarios. ¿Podríamos incluir en esas comparecencias [manifestaciones del derecho de representación política (art. 23.2 CE)] la de los miembros del Consejo General del Poder Judicial, como control de la acción de un órgano constitucional (poder público)?

De manera extensiva los Reglamentos parlamentarios (incluidos los autonómicos) se refieren a las comparecencias (art. 44.1 del Reglamento de las Cortes Valencianas) no sólo de los miembros del gobierno sino de: «... altos cargos de la administración de la Generalidad, así como autoridades y funcionarios públicos competentes por razón de la materia objeto del debate, para que informen acerca de los extremos sobre los que fueran consultados.» Incluso, se llega a incluir la solicitud de comparecencias a otras personas con la misma finalidad.

Es cierto que el control parlamentario al ejecutivo no ha sido un tema pacífico en el terreno de los hechos, ni en el de las ideas. ¿Qué abarca el control parlamentario sobre el ejecutivo? Los órganos constitucionales, como sería el caso que nos ocupa del Consejo, ¿deberían formar parte de los sujetos destinatarios del control de las Cámaras, respondiendo a un concepto amplio de control que abarque a «todos» los poderes públicos?

Quiénes son los sujetos controlables y destinatarios del control parlamentario no es algo completamente perfilado. «...Una extensión problemática. La idea básica de esta interpretación es que es posible extender el concepto de control a todo el área de los poderes públicos, incluidas las Administraciones públicas y ahora también a las autoridades administrativas independientes y a las instituciones europeas [...] se trata de una propuesta que pone el acento en la responsabilidad política difusa, es decir, aquella responsabilidad que se anuda al ejercicio, o una pretensión de ejercicio, de poder político aunque el sujeto que lo ejerce no esté ligado por una relación institucional al Parlamento...» ${ }^{27}$

Un órgano constitucional independiente no puede significar un órgano constitucional irresponsable. Ahora bien, en ese diálogo de ponderación necesaria una responsabilidad política «institucional» estrangularía por asfixia una independencia, imprescindible y configuradora de la esencia del órgano de gobierno del poder judicial (art. $122 \mathrm{CE}$ ).

27 García Roca, J. e Ibrido, R., «El control parlamentario en Italia. Un estudio comparado sobre el concepto y algunas de sus mejores prácticas: el comité para la legislación y la comisión de presupuestos», en El control del Gobierno en Democracia, XIX Jornadas de la AELPA, 2013, pág.15-116; 
Pero no cabe más responsabilidad y control, suprimiendo al mismo tiempo las herramientas que lo articulan. $\mathrm{Y}$ en este sentido, el legislador del nuevo Consejo debería haber empezado por argumentar, de manera suficiente, el sentido y necesidad de este artículo, su justificación jurídica y conveniencia u oportunidad política.

\section{Elección de los Vocales}

La interpretación del artículo 122.3 de la Constitución es y ha sido también, un importante problema. El pecado original del Consejo es la designación de sus veinte integrantes, que ha quedado, de manera indirecta [...] en manos de los partidos políticos... ${ }^{28}$

\subsection{Las novedades de la Ley}

La ley orgánica 4/2013 explica que la reforma en el sistema de designación de los veinte vocales se articula sobre la base de dos elementos: a) garantizar la máxima posibilidad de participación en el proceso de todos los miembros, asociados o no, de la carrera judicial y, b) otorgar al Congreso y el Senado la plena responsabilidad en la designación de los mismos, en cuanto cámaras representantes de la soberanía popular.

Cada cámara elegirá 10 vocales por mayoría de tres quintos, cuatro entre juristas de reconocida competencia con más de quince años de ejercicio de su profesión y, seis procedentes del turno judicial (art. 566).

Para presentarse por el turno de juristas será necesario estar en servicio activo, tener el aval de 25 miembros de la carrera judicial en activo o contar con el aval de una asociación legalmente constituida (art. 573 y 574). Tanto los jueces, como los magistrados o asociaciones profesionales podrán avalar a un máximo de 12 candidatos.

La designación de los doce vocales del turno judicial deberá respetar como mínimo (art. 578.3) la siguiente proporción: tres magistrados del Tribunal Supremo, tres magistrados con más de 25 años de antigüedad en la carrera judicial y seis jueces o magistrados sin sujeción a antigüedad. Si dentro de alguna de las categorías referidas no hubiere candidatos, la vacante acrecerá el cupo de la siguiente, respetando el orden indicado ${ }^{29}$.

${ }^{28}$ IÑIgUeZ HernándeZ, D., «El autogobierno judicial, hacia una edad de hielo», op. Cit., pág. 28;

${ }^{29}$ Señala el Informe del CGPJ: «...Según el último escalafón de la carrera judicial, cerrado el 31 de enero de 2012, hay un total de 81 magistrados del TS, más su Presidente; 4430 con cate- 
También surge como novedad el artículo 567.3, que permite a jueces y magistrados que no estén en servicio activo y que cuenten con más de quince años de ejercicio profesional, presentarse por el turno de juristas. Y podrán utilizar para el cómputo de los quince años, no sólo su experiencia jurídica profesional sino también los años de ejercicio en la carrera judicial. Lo que significa un claro perfil judicial en la potencial composición del Consejo.

El resultado final y la composición del Consejo en este séptimo mandato es la de un órgano con claro perfil judicial, con sólo un juez, doce magistrados, tres de ellos del TS (más el Presidente), dos Secretarios judiciales, dos Catedráticos de derecho (civil y constitucional), dos diputados, una Abogada experta en Derecho privado y una Abogada del Estado ante el Tribunal de Justicia de las Comunidades europeas. Un Consejo de 10 hombres y 10 mujeres; con cinco vocales miembros de la asociación Jueces para la Democracia, cuatro miembros de la Asociación Profesional de la magistratura y tres vocales (del turno judicial) no afiliados. Un órgano constitucional que suma diez vocales propuestos por el PP, siete por el PSOE, uno por CiU, uno por PNV y uno por IU; y además, entre sus vocales judiciales, D. Rafael Fernández Valverde, magistrado del Tribunal Supremo, repite como vocal puesto que ya lo fue entre 1996 y $2001^{30}$.

Mientras se escriben estas páginas la Asociación Judicial Francisco de Vitoria, la segunda más representativa en la carrera judicial, ha presentado ante el Tribunal Supremo una demanda contra el nombramiento de los 12 vocales judiciales y contra la designación de su Presidente ${ }^{31}$.

goría de magistrado, de los que sólo 1066 llevan más de 25 años en la carrera judicial y por tanto 3364 tienen menos de esa antigüedad, y por último, 537 con categoría de juez. Las cifras expuestas ponen claramente de relieve que las cuotas que se establecen para magistrados con más o menos de veinticinco años de antigüedad y Jueces no son, en ningún caso, respetuosas con la proporcionalidad que se alega, y comportan la limitación de las posibilidades de elección por parte de Diputados y Senadores...»

${ }^{30}$ La ley orgánica del Poder Judicial establece prohibición para ser elegido vocal: 567.5.:»... En ningún caso podrá recaer la designación de vocales del Consejo General del Poder Judicial en vocales del Consejo saliente.»

${ }^{31}$ El recurso denuncia la ilegitimidad de los nombramientos de los vocales judiciales y del Presidente del CGPJ: «...El artículo 578 de la LOPJ, en su apartado segundo, señala que en la designación de los vocales del turno judicial, las Cámaras tomarán en consideración el numero existente en la carrera judicial, en el momento de proceder a la renovación del Consejo General del Poder Judicial, de Jueces y magistrados no afiliados y de afiliados a cada una de las distintas Asociaciones Judiciales»; ello supone que, al menos seis de los vocales nombrados, hubieran debido ser no asociados. La conclusión es clara: o los representantes de la soberanía popular no saben de leyes, o no saben matemáticas. $\mathrm{O}$, tal vez, ni las leyes, ni las matemáticas les importen verdaderamente con tal de controlar a los jueces, lo que no deja de ser sorprendente.» La demanda ha 


\subsection{La evolución y diversos modelos de elección de los miembros del CGPJ}

Las críticas sobre todos los modelos han sido muy abundantes: «...La composición del Consejo, acaba reproduciendo prácticamente las dos grandes tendencias partidistas (PSOE y PP), con escasa entrada a miembros propuestos por asociaciones profesionales minoritarias, o por candidaturas de jueces independientes, o por partidos minoritarios dentro de las Cámaras. Aunque los vocales elegidos por las Cámaras no reciben un mandato imperativo de éstas, sí parece existir un mandato subliminar que responde a sus convicciones ideológicas o asociativas. Y la imagen que ello genera en el justiciable es la de un órgano altamente politizado...» ${ }^{32}$.

1. El primer modelo (1980-1985) regulado por la ley orgánica 1/1980, de 10 de enero del Consejo General del Poder Judicial, se basaba en la designación por los jueces, de los vocales judiciales y por el Parlamento, de los vocales procedentes de la categoría juristas de reconocida competencia.

Decía el artículo octavo de la ley de 1980: «Los doce vocales de procedencia judicial serán elegidos entre jueces y magistrados pertenecientes a todas las categorías judiciales, en los términos establecidos en la presente Ley. Integrarán el Consejo tres magistrados del Tribunal Supremo, seis magistrados y tres Jueces.»

Este Consejo, tal como había sido diseñado por la Ley padeció un claro dominio y control de la Asociación Profesional de la magistratura, asociación mayoritaria, que reunía por aquél entonces el $70 \%$ de los jueces y magistrados en servicio activo.

2. El segundo modelo (1985-2001) se regulaba en la ley orgánica 6/1985, de 1 de julio del poder judicial y concentraba el nombramiento de los veinte vocales del Consejo en manos del Parlamento ${ }^{33}$.

sido recientemente admitida por el TS tan sólo en cuanto al nombramiento del Presidente del TS, D. Carlos Lesmes.

32 Serra Cristóbal, R., «La elección de los miembros del Consejo General del Poder Judicial. Una propuesta de Consejo más integrador e independiente», en Teoría y Realidad Constitucional, n. ${ }^{\circ}$ 31, UNED, Madrid 2013, pág. 305; IÑIgUEZ HERNÁNDEZ, D. : «El modelo fallaba estrepitosamente porque estaba construido sobre una premisa falsa y extremista: el desbordamiento del sentido natural de la independencia judicial», en El Fracaso del autogobierno judicial, Civitas 2008 pág.227228; Ver también, Díez-Picazo, L. M., López Aguilar, J. F., López Guerra, L., LuCas Murillo DE la Cueva ,P., y Rodríguez Zapata, J. en «Encuesta sobre el pacto de Estado para la reforma de la Justicia», en Teoría y Realidad Constitucional, 8-9, UNED, 2002, págs. 11 y ss.

${ }_{33}$ La propuesta que acabaría siendo el segundo modelo de designación de los vocales del CGPJ fue el resultado de una enmienda presentada por el diputado Bandrés, «...la enmienda de 
Este segundo modelo, nacido para evitar el corporativismo de las asociaciones, sustituyó parcialmente éste para introducir un reparto de cuotas políticas partidistas.

Ello fue objeto de un recurso de inconstitucionalidad que cuestionaba si este nuevo modo de proceder resultaba compatible con el art. 122.3 de la CE y el TC asumiendo una forzada interpretación "conforme» advirtió de los riesgos del modelo pero apostó por una línea interpretativa salvadora de la constitucionalidad: «...El fin perseguido es, de una parte, el de asegurar la presencia en el Consejo de las principales actitudes y corrientes de opinión existentes en el conjunto de jueces y magistrados en cuanto tales, es decir, con independencia de cuáles sean sus preferencias políticas como ciudadanos y otra, la de equilibrar esa presencia con la de otros juristas que, a juicio de ambas Cámaras, puedan expresar la proyección en el mundo del Derecho de otras corrientes de pensamiento existentes en las sociedad [...] el riesgo sería atender sólo a la división de fuerzas existentes en el seno de las Cámaras y distribuir los puestos a cubrir entre los distintos partidos [...] la existencia y aún la posibilidad de ese riesgo [...] no impide una interpretación adecuada a la Constitución» (STC108/1986, de 29 de junio $)^{34}$.

3. El tercer modelo (2001-2013) se regulaba en la Ley Orgánica 2/2001, de 28 de junio, que introducía el denominado sistema de «doble legitimidad». Por un lado la legitimidad de la propuesta por jueces y magistrados de los candidatos judiciales y por otro lado, la legitimidad parlamentaria en la elección final de los mismos.

Los arts. 111-116 regulaban el procedimiento y la verdadera novedad se producía en la designación de los doce vocales del turno judicial que serían propuestos, de acuerdo a ciertas exigencias, por los jueces y magistrados y votados en las Cámaras.

«... Todo esto nos conduce a dos conclusiones: la adscripción a una asociación parece haberse convertido en una necesidad [...] y en segundo lugar, se observa una excesiva politización en el propio momento de la elección de vocales de entre las listas, proceso en el que los partidos políticos parecen jugar a un

Juan Mari Bandrés y mía propia (es la declaración del diputado del PSOE Brú Purón) nació en el Grupo Socialista del Congreso Debíamos detraer de la endogamia profesional conservatista la designación de los componentes de un poder del Estado. Nunca quisimos cuotas partidistas...», en IÑIgUeZ HernáNDEZ, D., op. cit. pág. 237;

34 Serra Cristóbal, R., «...un modelo que acabó propiciando un sistema de pactos, entre los partidos mayoritarios en las Cámaras, sobre quienes iban a formar parte de tal órgano, con un criterio de selección que pareció obedecer más a razones de lealtad al partido político que al prestigio indiscutible, independencia probada, o excelencia profesional...», en op. cit. pág. 302 y ss. 
reparto de cuotas. Los grupos parlamentarios deciden cuántos pedazos del pastel le corresponden a cada uno y luego cada uno de ellos escoge el sabor de la parte que le ha correspondido.... ${ }^{35}$

\subsection{Algunos problemas sin resolver}

Observamos que la sucesión de modelos en la designación de vocales ha sido un fiel reflejo del constante afán de solucionar los problemas que cada modelo en la práctica iba planteando.

El diagnóstico previo a la ley vigente castigaba la fuerte presencia de las asociaciones y el reparto de cuotas de los grupos parlamentarios. El artículo 578.2 de la ley vigente dice que «...las Cámaras tomarán en consideración el número existente en la carrera judicial, en el momento de proceder a la renovación del CGPJ, de jueces y magistrados no afiliados y afiliados a cada una de las distintas Asociaciones judiciales.» Pero la duda que no resuelve el legislador es: ¿cómo y cuánto se tomara en consideración tal proporción? puesto que en el apartado siguiente de ese mismo artículo (578.3) se impone como mínimo una proporción al Consejo de: 3 magistrados del TS, 3 magistrados con más de 25 años y 6 jueces o magistrados sin antigïedad. La Constitución no exige que todas las categorías judiciales estén representadas en el Consejo, sino que sean elegibles miembros de todas sin discriminación.

El Informe del CGPJ recuerda que: «...no se considera justificada la limitación de las Cámaras a la hora de decidir, conforme a los principios de mérito y capacidad, [...] los candidatos finalmente designados, máxime cuando es obvio que los procedentes de la categoría de juez, en general, no contarán con la experiencia de quince años en el ejercicio de la Judicatura ni de ninguna otra profesión jurídica, lo que sí se exige a los vocales no judiciales...» No podemos olvidar que los principios de representación y pluralismo en los vocales del Consejo no deben verse constreñidos más que por los principios de mérito y capacidad y por la escrupulosa observancia de la legalidad en los procesos de designación. Imponer un «corsé» (para el caso de los vocales judiciales) en aras de la representatividad de todas las llamadas categorías profesionales no creemos que abunde en un mayor pluralismo, ni desde luego asegure un mayor mérito y capacidad en nuestros vocales.

Otro problema sería el «excesivo perfil judicial» puesto que la nueva ley permite presentarse por el turno de juristas a jueces y magistrados que no estén en activo y les permite computar los quince años de ejercicio profesional contan-

35 Serra Cristóbal, R., en op. cit. pág. 304. 
do con sus años de ejercicio en la carrera judicial. Y la última facilidad (para presentarse por el turno de juristas) la encontramos en el artículo 567.3: «... Quien, deseando presentar su candidatura para ser designado Vocal, ocupare cargo incompatible con aquél según la legislación vigente, se comprometerá a formalizar su renuncia al mencionado cargo si resultare elegido.» Luego todo parece indicar que un juez o magistrado en activo podría presentarse por el turno de juristas y renunciar a su cargo si fuese elegido. Afortunadamente en el Consejo vigente no ha ocurrido.

Por último, la disposición adicional $2 .^{\text {a }}$ contempla las exigencias del artículo 14 la ley orgánica 3/2007, de 22 de marzo, para la igualdad efectiva de hombres y mujeres.

Los problemas de la designación de vocales se plasman en dos fases (diseñadas teóricamente), por un lado, la de propuesta o primera selección a modo de primer filtro, en la que mérito y capacidad deberían ser los únicos objetivos a perseguir, si bien aderezados tan sólo con la apertura a todas las categorías judiciales y jurídico-profesionales. Y un segundo momento o fase que obviamente recoge el trabajo de la primera, con un discurso relativo al diseño de un procedimiento de selección seguro, legítimo, fiable, representativo, que se asegura con una mayoría reforzada en las Cámaras parlamentarias (tal como se recoge en la LOPJ) y que cuadra sólo, de manera forzada, con la prescripción de categorías del 578.3.

La excesiva y manipuladora presencia de las fuerzas políticas en las Cámaras a la hora de elegir a los vocales, el pacto político en la sombra y sus reflejos en las «flexibles» interpretaciones de los plazos de renovación son el escenario de nuestros Consejos. El buen diseño de mecanismos de elección de los vocales está íntimamente unido a los problemas de renovación de los mismos.

Tal vez la renovación parcial de los vocales, como ocurre en otros órganos constitucionales y la sanción al incumplimiento de los plazos de renovación, por ejemplo con un procedimiento «b» (intuitivamente y, más que probablemente, no llegaría nunca a ponerse en funcionamiento) que por sorteo/insaculación decidiera quién va a ocupar, en caso de no obtenerse las mayorías exigidas en plazo, el cargo de vocal, introducirían aires de regeneración u oxigenación en unas inercias perversas de juego político difíciles de erradicar.

\section{Eliminación de las situaciones de bloqueo en la renovación del CGPJ}

Como decíamos en anteriores líneas muy en conexión con el modo de designación de los vocales está el diseño de un adecuado proceso de renovación del órgano. Es conocida la dificultad que entraña la renovación de los órganos cons- 
titucionales. Basta con echar la vista atrás para constatar, a través de las fechas, el incumplimiento del mandato constitucional de nombrar cada cinco años los vocales de este órgano.

La nueva Ley articula tres supuestos en la renovación del Consejo:

a) Renovación parcial/prórroga parcial. Un Consejo «cojo» y según el legislador una «mera circunstancia»

La LOPJ introduce una fórmula novedosa de renovación en su artículo 570. Su razón de ser según la Exposición de Motivos, es: «la eliminación de las situaciones de bloqueo en la renovación».

«...Si el día de la sesión constitutiva del nuevo Consejo General del Poder Judicial no hubiere alguna de las Cámara procedido aún a la elección de los vocales cuya designación le corresponda, se constituirá el Consejo General del Poder Judicial con los diez Vocales designados por la otra Cámara y con los Vocales del Consejo saliente que hubieren sido designados en su momento por la Cámara que haya incumplido el plazo de designación, pudiendo desde entonces ejercer todas sus atribuciones...»

El legislador se refiere a esta posibilidad, en el art. 570.5: «la mera circunstancia de que la designación de Vocales se produzca una vez constituido el nuevo Consejo (puesto que en este caso la Cámara incumplidora nombra después a sus correspondientes vocales) no servirá de justificación para revisar los acuerdos que se hubieren adoptado». Nuestro legislador esclavo de sus palabras y dueño de sus silencios, señala que tal incumplimiento no es más que algo anecdótico, aledaño o circunstancial, «una mera circunstancia».

Se articula una posibilidad de renovación parcial de un órgano constitucional sin que la Constitución así lo prevea, a diferencia de lo que en su día nuestra Carta Magna sí contempló para otros órganos como es el caso de la renovación por tercios del Tribunal Constitucional, art. 159.3 CE.

¿Qué efectos comporta la novedad que introduce el artículo 570.1 de la nueva ley?:

1) El legislador acepta como posible la no renovación en tiempo por una Cámara. Lo que comporta el incumplimiento de su obligación prescrita por la Constitución. Ello resulta paradójico con el motivo que justifica en la Exposición de Motivos esta novedad, esto es, la eliminación de las situaciones de bloqueo. ¿Cómo se pretende eliminar un potencial bloqueo, aceptando el incumplimiento de la Cámara, estableciendo una solución o alternativa como respuesta a un incumplimiento? 
2) La posibilidad de que algunos vocales tengan un mandato inferior a cinco años. El artículo 570.3 señala: «El nombramiento de vocales con posterioridad a la expiración del plazo concedido legalmente para su designación no supondrá, en ningún caso, la ampliación de la duración de su cargo más allá de los cinco años de mandato del Consejo General del Poder Judicial para el que hubieren sido designados, ...»

3) La posibilidad de que algunos vocales tenga un mandato superior a cinco años. Podrán ser superiores a cinco años los mandatos tanto de los vocales prorrogados por la Cámara incumplidora, como los de todos, si estamos en el supuesto más adelante indicado de «consejo en funciones».

4) La posibilidad de que un Consejo «cojo», esto es, que empieza su mandato sólo al $50 \%$ renovado, ejerza todas sus atribuciones, incluida la designación del Presidente del CGPJ y del TS, por tanto.

5) Los acuerdos o decisiones tomadas por el Consejo «cojo», no serán revisados por el nuevo Consejo ya sí renovado en su totalidad y a posteriori. Este último efecto, a nuestro juicio, constituye una invitación/incentivación a la no renovación en tiempo.

b) Prórroga total/ no renovación del Consejo por incumplimiento de las dos Cámaras en la designación de los vocales. Un consejo «en funciones»

También cabe la posibilidad de que el incumplimiento en la designación de vocales sea de las dos Cámaras. Artículo 570.2: «Si ninguna de las dos Cámaras hubieren efectuado en el plazo legalmente previsto la designación de los Vocales que les corresponda, el Consejo saliente continuará en funciones hasta la toma de posesión del nuevo, no pudiendo procederse, hasta entonces a la elección de nuevo Presidente del Consejo General del Poder Judicial.»

c) Renovación plena y cumplimiento del mandato constitucional. Un Consejo renovado legítimamente, (en cumplimiento de la legalidad).

Este procedimiento se lleva a cabo cuatro meses antes de la expiración del mandato de los vocales salientes. Dentro de ese plazo, el Presidente del CGPJ notifica a los Presidentes de las Cámaras los datos del escalafón y del Registro de Asociaciones Judiciales y fija el plazo de presentación de candidaturas (vocales judiciales). Se pone en marcha el cumplimiento de la ley Orgánica en sus artículos 572-578 para la elección de los vocales judiciales que tendrán un mes para presentar. Ya no se pueden aplicar los artículos 204-205 del Reglamento del Congreso y 184 a 186 del Reglamento del Senado, sino que habrá que aplicar 
lo que establece la Disposición Derogatoria: «...El día en que se constituya el primer Consejo elegido de conformidad con lo dispuesto en la presente ley Orgánica quedará derogado el resto del Título II del Libro II de la ley Orgánica 6/1985, de 1 de julio del Poder Judicial, así como cuantos preceptos de dicha Ley y otras disposiciones de igual o inferior rango se opongan a lo establecido en la presente ley orgánica...» Una vez expirado el mandato del Consejo saliente, en los cinco días posteriores a la sesión constitutiva del nuevo Consejo, los nuevos vocales designados tomarán posesión.

Santamaría Pastor entiende que la «prorogatio» es la salida más natural y menos costosa al bloqueo de la renovaciones pero advirtiendo al mismo tiempo de una serie de efectos negativos importantes: a) la prorogatio produce una tendencia natural a retroalimentarse aceleradamente, ocultando «dulce y suavemente» a sus verdaderos protagonistas, los partidos políticos; b) es un factor de deslegitimación del órgano prorrogado y de las decisiones que adopte; c) produce una sensación permanente de interinidad e invita a la inactividad o pasividad; d) genera sospechas de «lealtad partidista» en los que con posterioridad lleguen a ser nombrados. De ahí que de acuerdo con este autor entendamos que la existencia de «plazos preclusivos» deba ser la solución ${ }^{36}$. Otros autores, como Aguiar de Luque ${ }^{37}$ consideran más conveniente contemplar la renovación parcial que, por otra parte, pudo haber contemplado el constituyente y no hizo.

\section{Ejercicio a tiempo parcial del cargo de vocal}

Por primera vez el Consejo General del Poder Judicial tendrá dos modalidades de vocales, los que estén a tiempo parcial y los que integren la Comisión permanente (art. 579).

36 Santamaría Pastor, J. A., «La prorogatio de los órganos constitucionales. Apuntes mínimos sobre un tema que no lo es.» en Revista Española de Derecho Constitucional, n. 84, septiembre-diciembre 2008, pág. 11-26; Resulta también muy interesante el trabajo de GARCía Roca, J., «La selección de los magistrados constitucionales, su Estatuto y la necesaria regeneración de las instituciones» en Revista General de Derecho Constitucional, IUSTEL, N. 15, 2012; este trabajo explica, a juicio del autor, que la prorogatio de los magistrados del TC (art. 17.2 LOTC) en el ejercicio de sus funciones se ha utilizado como norma de cobertura en claro fraude de la Constitución y es una clara violación del término constitucional de nueve años para el cual son elegidos los magistrados. Reflexión que podemos utilizar para los vocales del Consejo.

37 Aguiar De Luque, L., «Una nueva reflexión sobre la prorogatio de los órganos constitucionales. Una discrepancia y algunas puntualizaciones» en Revista Española de Derecho Constitucional, n. 85 , enero-abril 2009 , págs. 83 y ss. 
Será el Pleno el encargado de designar los vocales de la Comisión Permanente, formada por el Presidente, tres vocales judiciales y dos designados por el turno de juristas. Con excepción de la comisión disciplinaria, dice el legislador, «se procurará la rotación anual» de esta comisión en al ánimo de que todos los vocales formen parte de ella durante al menos doce meses. Pero en todo caso, el artículo 601 establece que será el Reglamento de Organización y Funcionamiento del CGPJ (ROF) el que en último extremo y por razones de «transitoria imposibilidad» o «ausencia justificada» decida la sustitución de los vocales en esta Comisión permanente.

Las razones de tal novedad se exponen en la Exposición de Motivos: a) una mayor cercanía de los vocales a la realidad que han de gobernar; b) la coherencia con el nuevo diseño de organización y funcionamiento del CGPJ que otorga un renovado y fuerte protagonismo al cuerpo de Letrados del Consejo; c) mayor agilidad y eficacia pues la Comisión permanente asume todas aquellas funciones que no estén encomendadas al Pleno o a alguna de las comisiones legalmente previstas; d) incrementar la posibilidad de acceder al Consejo a personas que hasta ahora no habían mostrado tal interés precisamente por la exigencia de interrumpir su actividad profesional.

Varios preceptos normativos quedan «afectados»: a) La Constitución dice en su artículo 127.1CE que jueces y magistrados mientras estén en activo, no podrán desempeñar otros cargos públicos, ni pertenecer a partidos políticos o sindicatos. b) Se deroga el artículo 117 de la LOPJ y se rompe con la tradición que desde 1980, ininterrumpidamente, se había venido manteniendo de «incompatibilidad del cargo de vocal con cualquier otro puesto, profesión o actividad pública o privada, por cuenta propia o ajena.» Tal vez romper una práctica de tantos años, requiera una profunda justificación que desde luego la ley no ofrece, y así también lo cree el informe del Consejo. c) Además se incumplen los artículos 389.2 y 5 . de la LOPJ que señalaban: «El cargo de juez o magistrado es incompatible: ...con cualquier cargo de elección popular o designación política del Estado, Comunidades autónomas, Provincias y demás entidades locales y organismos dependientes de cualquiera de ellos [...] Con todo empleo, cargo o profesión retribuida, salvo la docencia o investigación jurídica, así como la producción y creación literaria, artística, científica y técnica, y las publicaciones derivadas de aquélla, de conformidad con lo dispuesto en la legislación sobre incompatibilidades del personal al Servicio de las Administraciones públicas» ${ }^{38}$.

Pero además, podríamos encontrar una serie de efectos, que se producen con tal novedad y que habrá que analizar, a saber:

I. Se produce una categorización entre vocales con dedicación exclusiva en el Consejo y vocales con dedicación parcial. Ambas categorías con: distin-

${ }^{38}$ La Disposición Derogatoria en el apartado tercero de la LOPJ. 
ta retribución económica, con dedicación profesional parcial o exclusiva, con un status distinto de régimen en activo o de «servicios especiales», con distinta eficacia de sus decisiones (sólo son firmes las del Pleno y la Comisión permanente).

II. Y a la inversa, se produce una diferenciación entre jueces y magistrados y entre aquellos jueces y magistrados que además son vocales del Consejo, con la proyección que potencialmente corresponda de tal distinción en el ejercicio de la función jurisdiccional.

III. Las dudas sobre «compatibilidades». Se suscita como duda la interpretación del artículo 580.1 de la LOPJ que establece: «... 1. El ejercicio de la función de vocal del Consejo General del Poder Judicial será incompatible con cualquier otro cargo público, electivo o no electivo, con la sola excepción en su caso del servicio en el cuerpo al que pertenezcan...»

¿Significa esto que los vocales judiciales a tiempo parcial no pueden estar en órganos de gobierno de Juzgados o Tribunales? Las respuestas a esta cuestión serán decisivas. Si el legislador encuentra aquí supuestamente pérdida de la necesaria «imparcialidad objetiva» (incompatibilidad entre la pertenencia al gobierno del poder judicial y el gobierno de un concreto órgano judicial), ¿qué razones, a «sensu contrario», le llevan a confiar que no habrá tal perdida de «imparcialidad objetiva» en el juez o magistrado que ejerce su función jurisdiccional y está al mismo tiempo en el gobierno de un determinado órgano judicial?; situación que hasta la fecha, por otra parte, se ha venido produciendo. Y ello además con la aceptación del legislador previamente de la compatibilidad entre ser gobierno del poder judicial (a tiempo parcial) y ejercer la función jurisdiccional. «... la existencia de compatibilidad de las funciones propias de vocal del CGPJ con las particulares de la profesión jurídica que en cada caso se ejerza, puede originar graves problemas [...]» ¿es razonable que un magistrado que ha concursado a una plaza, o a un puesto de libre designación, o que puede ser sancionado por una determinada conducta, sea quien decida un asunto litigioso cuya dirección letrada o representación técnica corresponde a un vocal del CGPJ? ¿O puede decidir con plena libertad un vocal magistrado acerca de una cuestión que afecta a un compañero suyo con quien al día siguiente tiene que compartir deliberación? ${ }^{39}$

IV. La «inexistencia de causa justificadora coherente y suficiente». Si una de las razones que baraja el legislador en la Exposición de Motivos para introducir esta figura del vocal a tiempo parcial es la conveniencia y necesidad

39 Banacloche Palao J., «La insólita reforma de la organización y funcionamiento del Consejo General del Poder Judicial» en Diario La Ley, n. ${ }^{\circ}$ 8126, Sección Tribuna, 15 julio 2013, Año XXXIV, Editorial, La Ley. 
de «mayor cercanía a la realidad que han de gobernar» los vocales. Esta cercanía, ¿no es más necesaria aún si cabe para los vocales que, realmente durante un año y por ser miembros de la Comisión permanente tienen en sus manos el grueso de las competencias del Consejo? ¿O es que se les va a permitir a los integrantes de la Comisión permanente su distanciamiento o desconexión con la realidad? O tal vez, añadiendo una última reflexión en este sentido, ¿no será que la «frugalidad» del razonamiento de la «cercanía» se pone aún más de relieve al invertir los términos del mismo?

V. La potencial «tiranía» de la Comisión Permanente. Como hemos expuesto en líneas anteriores, la ley señala que será el Pleno quien nombre cada año a la Comisión permanente, pero el artículo 601.3 de la ley establece que el Reglamento de Organización y Funcionamiento, (luego reglamento ferenda), será el que en último caso determine tal composición. «El CGPJ determinará, en el Reglamento de Organización y Funcionamiento, los casos y la forma en que, por razones de transitoria imposibilidad o ausencia justificada a las sesiones de la Comisión Permanente, deba procederse a la sustitución de los vocales titulares por otros vocales, a fin de garantizar la correcta composición y el adecuado funcionamiento». Sólo los vocales de la Comisión Permanente tendrán el conocimiento pleno de la actividad del Consejo por su dedicación en exclusiva. Gozando en consecuencia de un estatus especial con relación al resto de vocales.

Se añade una clausula final muy laxa que apelando a motivos de «transitoria imposibilidad» o «ausencia justificada» permite, en último extremo, incidir de manera directa en la composición de la Comisión permanente ${ }^{40}$. Siempre, dice el artículo, en aras de «garantizar la correcta composición y el adecuado funcionamiento». Y esta última reflexión debemos acompañarla del grueso de competencias que con la nueva ley asume la Comisión Permanente [que son todas menos las que siguen en manos del Pleno, la Presidencia, la Comisión Disciplinaria, de Igualdad o de Asuntos Económicos (art. 602 LOPJ)] y del régimen de sus actos, pues serán firmes

40 Art. 601.2: «...Con excepción de los miembros de la Comisión Disciplinaria, se procurará la rotación anual del resto de los vocales en la composición anual de la Comisión Permanente.» Señala García-Escudero Márquez, P., que: «...el lenguaje jurídico debe proporcionar: univocidad semántica, economía léxica y precisión conceptual. [...] la vaguedad, en la que la incertidumbre en el significado deriva no de un campo de referencia plural, sino indefinido. [...] Cuando el fenómeno de la vaguedad se refiere a hechos futuros se produce la denominada por Waismann textura abierta del lenguaje: todos los términos son potencialmente vagos en cuanto que el uso futuro de los mismos puede presentar circunstancias no tenidas en cuenta al elaborar dicho concepto, y respecto de las cuales el sentido común del termino no determina su aplicación o inaplicación.» En Manual de Técnica Legislativa, Civitas 2011, pág. 175-179; 
y sólo recurribles ante la jurisdicción contencioso-administrativa y no ante el Pleno ${ }^{41}$. Pero además ante una sección especial dentro de la referida sala, generando una excepción al régimen común de los recursos de los que conoce la Sala de lo contencioso del Supremo, carente de justificación (de la que nos ocuparemos más adelante).

5. La nueva estructura y reparto de competencias entre los órganos del CGPJ, en especial, su Vicepresidente (del TS)

Una Comisión Permanente fuerte, protagonista y con vocales en «dedicación exclusiva»

Desaparece la Comisión de Calificación cuyas competencias, en gran parte, son asumidas por la Comisión permanente. Se pretende huir de un modelo presidencialista, y sin mermar las competencias que deben seguir en el Pleno, todas aquellas que no están en manos de éste pasarán a la Comisión Permanente y no al Presidente. Los órganos del Consejo serán: el Presidente y el Vicepresidente del Tribunal Supremo, el Pleno, la Comisión Permanente, la Disciplinaria, de Asuntos Económicos y la de Igualdad.

El Presidente del CGPJ, que lo será también del TS por prescripción constitucional (art. 122.3 CE), adquiere ciertas competencias nuevas como: a) dirigir la comunicación institucional (art. 598.8. ${ }^{\circ}$ LOPJ), b) nombrar y cesar al Director del Gabinete de la Presidencia, al Director de la Oficina de Comunicación y al personal eventual al servicio del Presidente (art. 598.10. ${ }^{\circ}$ ), c) proponer al Pleno el nombramiento del Vicepresidente del TS, del Secretario General y del Vicesecretario General (art. 598.11. ${ }^{\circ}$ ). Pero el órgano que verdaderamente sale reforzado es la Comisión Permanente que se diseña de manera distinta en la forma y en el fondo. Su composición se ve incrementada en un vocal, ahora son cinco, con dedicación en exclusiva y sus acuerdos no serán recurridos en alzada ante el Pleno, como hemos explicado en líneas anteriores.

\section{Un Vicepresidente del Tribunal Supremo «alter ego» del Presidente del CGPJ}

Se crea por primera vez la figura del Vicepresidente del Tribunal Supremo que auxiliará y sustituirá al Presidente cuando lo establezca la ley. La justifica-

${ }^{41}$ Señala el artículo 638.2 de la LOPJ: «Los acuerdos del Pleno y de la Comisión Permanente pondrán fin a la vía administrativa y serán recurribles ante la Sala de lo Contencioso-administrativo del Tribunal Supremo. El conocimiento de estos asuntos corresponderá a una sección integrada por el Presidente de la Sala de los Contencioso-administrativo del Tribunal Supremo, que la presidirá, y por los demás Presidentes de Sección de dicha sala.» 
ción que se ofrece para la creación de esta nueva figura radica en que en los últimos treinta años «el Consejo ba absorbido casi por completo a los sucesivos Presidentes» privando por tanto al Tribunal Supremo de un auténtico Presidente. Para evitarlo se crea este órgano como apoyo y persona de confianza del Presidente, de ahí que será propuesto por este al Pleno y nombrado por éste por mayoría absoluta. Tendrá que ser un magistrado del TS en activo y reunir los requisitos para ser Presidente de sala del TS. Su cese lo decidirá el Pleno por causa justificada y mayoría de tres quintos (art. 589 de la LOPJ)

Pero lo que realmente resulta sorprendente es el elenco de facultades que se atribuyen a esta figura del Vicepresidente del TS pues podrá incluso ejercer «en funciones» el cargo de Presidente del TS y del CGPJ en los casos de cese anticipado del Presidente y podrá sustituirle en supuestos de vacante, enfermedad, ausencia u otro motivo legítimo. Por último, se permite ejercer al Vicepresidente del TS por delegación del Presidente todas aquellas funciones que éste le delegue expresamente mediando causa justificada (art. 590 y 591 LOPJ). ¿Permite nuestra Constitución que un órgano como éste que no tiene cabida en el 122 CE desempeñe tareas y disfrute de un tratamiento como si de un órgano del CGPJ se tratara?

\section{Un Consejo «profesionalizado» a través de Letrados del Consejo General del Poder Judicial}

Entiende el legislador que como esta institución debe renovarse cada cinco años, ello implica una falta de «continuidad institucional» que podría ser paliada con la creación de un determinado número de miembros del cuerpo de Letrados del Consejo General del Poder Judicial que tengan carácter permanente, siendo elegidos por concurso-oposición en aras de garantizar la estricta observancia de los principios de mérito y capacidad. Un cuerpo destinado a realizar labores «técnico-jurídicas» dentro del Consejo (artículo 621 a 627).

\section{La aplicación de la regla de la mayoría simple con carácter general. El nuevo régimen de los Actos del Consejo}

Con la nueva ley y salvo excepciones, la regla general en la adopción de acuerdos será la mayoría simple, lo que pretende evitar el bloqueo en la toma de decisiones. El artículo 630 de la ley se refiere a «acuerdos de los órganos colegiados», lo que incluye al Pleno y a la Comisión Permanente, entre otros, y establece:

d.1. Acuerdos en el Pleno: Con carácter general (y salvo que la ley establezca cosa distinta) regla de la mayoría simple de los miembros presentes, 
art. 630.1 LOPJ. El artículo 129 LOPJ exigía al Pleno para que éste quedara válidamente constituido y pudiera adoptar acuerdos un mínimo de catorce miembros con asistencia de su Presidente. La vigente ley establece, (art. 600.4 LOPJ), con carácter general un mínimo de diez vocales y su Presidente para considerar el Pleno válidamente constituido. Luego, donde antes eran suficientes ocho votos, ahora bastarán seis. Además como la ley permite constituir un nuevo Consejo sólo renovando diez de sus veinte vocales, las sospechas de «politización» del órgano lejos de erradicarse, podrían verse incrementadas.

d.2. Para los acuerdos en la Comisión Permanente y con carácter general, nada dice claramente la ley sobre la «válida constitución para adoptar acuerdos» ${ }^{42}$ (art.601.3), es más, se reserva un cheque en blanco al ROF (Reglamento de Organización y Funcionamiento del Consejo) por lo que en principio y aplicando la regla de la mayoría simple de miembros presentes, bastarán cuatro votos para adoptar acuerdos, siendo el del Presidente de calidad en caso de empate.

Resulta además curioso este, (no sabemos si olvido o dejación del legislador en manos del ROF del Consejo), no detallar el quórum de válida constitución del órgano colegiado (Comisión Permanente) que más peso adquiere tras la nueva regulación. Y ello viendo que para el resto de órganos colegiados no es así: para el Pleno se exige, salvo supuestos excepcionales, un número mínimo de diez vocales más el Presidente (art. 600.4 LOPJ), para la Comisión Disciplinaria la asistencia de «todos sus componentes» (art. 603.3), para la Comisión de Asuntos Económicos la asistencia al menos de tres de sus componentes (art. 609.3) y para la Comisión de Igualdad la asistencia de todos sus componentes (art. 610.3).

d.3. Regulación del deber de voto y de determinadas "prescripciones formales y materiales de su ejercicio»: Se obliga a todos los vocales mediante el «deber inexcusable de asistir, participar y emitir voto válido» (art. 630.2). Asimismo los votos serán nominales y no podrán ser secretos, pero se mantiene como en la ley anterior el carácter reservado de las deliberaciones y el deber de los vocales de guardar secreto sobre éstas. Se prohíben la abstención, salvo que concurra causa legal para ello, y también el voto en blanco para los asuntos en «materia disciplinaria» y para las decisiones sobre $«$ recursos ${ }^{43}$.

42 Recordemos que en la antigua LOPJ el artículo 130.2 establecía: «La reuniones de la Comisión Permanente sólo serán válidas con asistencia de tres, al menos de sus componentes, entre los que deberá encontrarse el Presidente o quien válidamente le sustituya.»

${ }_{43}$ Que la realidad vivida por los distintos Consejos justifica este nuevo artículo 630 de la LOPJ, puede resultar comprensible, señala IÑIGUEZ HERNÁNDEZ, D., «...En las diferentes comisiones, como en el Pleno, los vocales no votan con arreglo a su procedencia profesional, su categoría judicial o incluso su procedencia geográfica, sino en bloques cuyo rasgo común es que integran a los propuestos por los respectivos partidos. [...] En 2001, el entonces Secretario de 
d.4. Los recursos sobre los actos del CGPJ: Los acuerdos del Pleno y de la Comisión Permanente pondrán fin a la vía administrativa y serán recurribles ante la Sala de lo Contencioso-administrativo del Tribunal Supremo. El principal efecto de esta novedad es que los acuerdos de la Comisión Permanente ya no serán recurribles ante el Pleno del CGPJ como sí lo eran en el artículo 143.1 de la LOPJ.

Además, va a conocer de estos recursos una sección especial de la referida sala del TS integrada por el Presidente de la Sala de lo contencioso que la presidirá y por los demás Presidentes de sección de dicha sala (esto es, un número de magistrados, seis concretamente, menor al Pleno de la Sala 3. ${ }^{\mathrm{a}}$ e incluso menor a los magistrados que integran la sala del art. 61 de la LOPJ). Conviene recordar que el derogado artículo 143.2 de la LOPJ decía: «Los actos, resoluciones y disposiciones emanados del Pleno serán recurribles en vía contencioso-administrativa ante la Sala correspondiente del TS.»

El sumatorio, y recapitulando, vendría a ser algo así como: una Comisión Permanente con un importante incremento de funciones (antes en manos del Pleno), con cinco vocales y sólo ellos con dedicación en exclusiva, sobre la que

Estado de Justicia, luego Ministro, Michavila afirmaba que su gobierno no iba a dar instrucciones a los vocales, quizá porque no ha sido nunca preciso: «la parcelación partidista se ha proyectado en la generalidad de sus prácticas», con sorprendente facilidad» en El Fracaso del Autogobierno judicial, Civitas 2008, pág. 312-313; Las crisis vividas por los diferentes mandatos del Consejo tuvieron siempre como protagonista el régimen de adopción de acuerdos y el reflejo partidista en el resultado final de éstos. Ahora bien, hechas estas reflexiones cabe la duda de si no afecta al «contenido» del derecho al voto del vocal del Consejo, una prescripción tal como la restricción del ejercicio de la abstención y del voto en blanco, aunque sea sólo para determinados casos. El artículo 24.1.c) de la LRJAP señala: «...no podrán abstenerse en las votaciones quienes, por su cualidad de autoridades o personal al servicio de las Administraciones Públicas, tengan la condición de miembros de órganos colegiados.», señala CARBONELL PORRAS, E., «... lo contrario equivale al no ejercicio de sus funciones. [...] El alcance de esta prohibición debe precisarse desde el punto de vista subjetivo. Por un lado, no es aplicable a los funcionarios que son miembros de órganos colegiados no en representación de la Administración ni de los intereses públicos, sino de un determinado colectivo, de los intereses que como personal de la Administración le son propios...»en Los Órganos Colegiados, CEPC, Madrid 1999, pág.189-191; Por el contrario, el informe del Pleno del CGPJ sobre el anteproyecto de la ley de reforma del Consejo se expresaba en los siguientes términos al respecto: «...el anteproyecto veta con carácter general la posibilidad de abstención, salvo que esta venga impuesta por la concurrencia de una causa legal o la naturaleza del asunto lo permita. En términos generales la medida merece una valoración positiva, en tanto que evita comportamientos renuentes o de indefinición que pueden repercutir negativamente en el funcionamiento de dicho órgano [...] la abstención será posible si tal posición no es incompatible con la esencia o cualidad de la resolución que se deba adoptar. El empleo de un concepto tan genérico y difuso arroja más incertidumbres que certezas y, por ello, sería preferible el uso de una fórmula más certera y precisa de cara a delimitar el ámbito de la abstención...». 
la ley no aclara un número mínimo de vocales para estar válidamente constituida (en el mejor de los casos cuatro, con voto de calidad del Presidente), cuyos actos son firmes en vía administrativa y sólo recurribles ante una sección «especial» de la sala tercera del TS.

\section{Transformación de la Comisión Disciplinaria. El nuevo órgano: el Promotor de la Acción Disciplinaria}

El procedimiento disciplinario deja de ser «inquisitivo» separando instrucción y sanción en órganos distintos. La LOPJ lo explica en los siguientes términos: «...no debe ser un mismo órgano quien decida la incoación del procedimiento, designe al instructor y, finalmente, sancione o no. Es verdad que la potestad disciplinaria es, por su propia naturaleza, un instrumento de gobierno; pero no por ello deja de ser una manifestación del ius puniendi del Estado cuyo ejercicio debe estar revestido de ciertas garantías fundamentales.»

La Ley regula en los artículos 603 a 608 el procedimiento disciplinario y añade que en «materia disciplinaria» si cualquier aspecto o extremo relativo al procedimiento, recurso o forma de los actos no está regulado en la LOPJ no será de aplicación con carácter supletorio la Ley de Régimen Jurídico de las Administraciones Públicas y del Procedimiento Común (art. 642.2). La Comisión disciplinaria estará nombrada por el Pleno (ahora ya no será necesaria mayoría de tres quintos como en el derogado artículo 132 de la LOPJ) y estará compuesta por siete vocales (dos más que antes), cuatro del turno judicial y tres entre juristas, dos vocales más que en la legislación anterior. Se exige para estar válidamente constituida y actuar, la asistencia de todos sus componentes y la presidencia del Vocal de origen judicial de más categoría y antigüedad.

Sus vocales tendrán un mandato de cinco años, luego no podrán formar parte de la Comisión Permanente y, además, ejercerán todo este tiempo con dedicación a tiempo parcial puesto que estarán en activo según su procedencia. ¿Puede resultar un problema ser miembro de la Comisión Disciplinaria y ejercer al mismo tiempo la función jurisdiccional? Los jueces y magistrados, art. 117.1 de la CE: «...independientes, inamovibles, responsables y sometidos únicamente al imperio de la ley.», serán ahora también (al estar en servicio activo) sancionadores de sus compañeros de profesión.

Las competencias serán: resolver los expedientes incoados por infracciones graves y muy graves y sancionar a Jueces y magistrados, siempre que la sanción no fuera la «separación del servicio» supuesto que se reserva para el Pleno (art. 599.10. ${ }^{a}$. 
Los acuerdos sancionadores serán recurribles en alzada ante el Pleno. Y, a su vez, la Comisión Disciplinaria, conocerá en alzada de los acuerdos sancionadores de los «órganos de gobierno internos» de los Tribunales.

Se crea un órgano nuevo denominado Promotor de la Acción Disciplinaria, nombrado por el Pleno entre magistrados del Tribunal Supremo y magistrados con más de 25 años de antigüedad. El Promotor ostenta la «consideración honorífica» de magistrado del TS mientras dure su designación y sus competencias son: a) La recepción de quejas y de «denuncias» sobre el funcionamiento de los órganos judiciales; b) La incoación de los expedientes disciplinarios; c) La «instrucción de los expedientes disciplinarios» y podrá actuar de oficio o a instancia de la Comisión Permanente. Sus decisiones son recurribles ante la Comisión Permanente; d) La presentación de cargos ante la Comisión Disciplinaria.

El día 31 de enero de 2014, el CGPJ eligió al magistrado del Tribunal Supremo Antonio Jesús Fonseca Herrero como primer Promotor de la Acción Disciplinaria en la historia de este órgano y con un resultado de veinte votos a favor y un voto en blanco. La figura del Promotor recuerda al Defensor del vínculo en Derecho canónico, los jueces no deberían ser juzgados por sus pares, sino por otros tribunales ad hoc, nombrados o compuestos de manera diferente, pero criterios como éstos se encuentran muy lejos de la mens legis y mens legislatoris de esta polémica LOPJ ${ }^{44}$.

\section{V. ÚLTIMAS REFLEXIONES...}

Ruíz Pérez anuncia que asistimos a la constatación del cambio radical operado por la figura del juez que de un personaje insignificante frente al encumbramiento del legislador durante buena parte del siglo XIX, se ha venido a transformar de manera irreversible en el actor central del drama capital del Derecho: la Justicia ${ }^{45}$.

Desde luego los frentes abiertos son bastantes. Habrá que esperar y observar cómo aplica el Consejo la nueva norma. Necesitamos conocer qué va a pasar con el nuevo Anteproyecto de Ley de reforma de la Ley orgánica del Poder Judicial. Habrá que estudiar qué dice el Tribunal Constitucional sobre la Ley orgánica 4/2013. Y habrá desde luego que atender al fallo del Tribunal Supremo sobre el cuestionado nombramiento del Presidente del Consejo

44 Pulido Quecedo, M., «El nuevo Consejo General del Poder Judicial» en Diario La Ley, n. ${ }^{\circ} 8126$, Sección Tribuna, 15 jul. 2013;

45 Ruiz Pérez, J. S., El juez protagonista: imparcialidad e independencia, en La Ley: Revista Jurídica española de doctrina, jurisprudencia y bibliografía, n. ${ }^{\circ} 4,1986$, pág. 988 y ss. 
Separación de poderes, Independencia Judicial, legitimidad parlamentaria, pluralismo político..., son todos «ejes estructurales» en la configuración de un órgano constitucional como es el Consejo General del Poder Judicial. Tales principios juridificados por la Constitución, desarrollados por el legislador, interpretados por el TC, desgastados por los intereses políticos son el escenario donde conviven lo mejor y lo más peligroso de la democracia.

Corren tiempos de «regeneración democrática» no sabemos qué entienden realmente los poderes públicos y las instituciones al respecto pero después de analizar la reforma 4/2013 de nuestro órgano de gobierno del poder Judicial podemos reflexionar que:

1. El Consejo General del Poder Judicial creado como garante de la independencia judicial interna y externa de jueces y magistrados y que se creó para extraer precisamente de las manos del gobierno la capacidad de influir, mediante nombramientos y sanciones, en la noble tarea de los únicos y exclusivos titulares de la iurisdictio, reduce drásticamente su potestad en manos del ejecutivo y de aquéllos que ocupan las posiciones jerárquicamente superiores de la carrera judicial. Se pierde autonomía en la gestión del presupuesto, se pierden competencias reglamentarias, se minimiza la capacidad de decidir y controlar la acción internacional del Consejo. El Consejo ahora y sobre todo es la Comisión Permanente, una significativa reducción de 20 vocales a seis.

No resulta fácil entender, según dice la exposición de motivos de la ley 4/2013, que la compatibilidad en el cargo (bien juristas en ejercicio, bien jueces y magistrados en activo) de los vocales que no estén en la Comisión permanente proporciona indudables ventajas, entre otras, la cercanía de los vocales a la realidad que han de gobernar. Tampoco resulta fácil admitir que la «buena administración y eficiencia económica, agilidad y eficacia» de la institución, se aseguren alumbrando diversas categorías de vocales, con distintos cometidos, competencias y sueldos. Pero lo que desde luego no resulta sensato aceptar, en aras de la regeneración democrática, es la deriva Presidencialista, «Comisión permanentista» y sobre los llamados «Letrados de su confianza» que ha experimentado el Consejo.

2. La designación de los vocales del Consejo, en este nuevo modelo, el cuarto de los ensayados desde que en 1980 lo presidiera por primera vez Federico Carlos Sainz Robles, propone huir del excesivo peso otorgado a las asociaciones en el modelo 2001 (alumbrando etapas bochornosas del Consejo como la de 2008) y que optimice e intensifique la participación de todos y cada uno de los miembros de la carrera judicial, al margen de 
su pertenencia o no a alguna asociación. En la reforma se busca una representación de todas las categorías judiciales, pero tal representación debe ser compatible con el principio de mérito y capacidad. Sacrificar una en virtud de la otra acaba afectando nocivamente la «razón de ser constitucional» de este órgano contenida en el artículo 122 de la Constitución. Se vuelve a la «representatividad dirigida» del modelo de 1980 al establecer prescriptivamente «el corsé» de: tres magistrados del TS, 3 magistrados con más de 25 años y seis jueces o magistrados sin antigüedad.

«El Consejo se crea para dos funciones que se considera que no pueden estar en manos del Gobierno: el nombramiento de cargos judiciales y el ejercicio de la disciplina, porque al juez se le controla con el palo y la zanahoria...», mediante estas perturbadoras declaraciones no se arroja sino más confusión a una difícil interpretación como es la del «mérito y capacidad» en los titulares de la salvaguarda de la independencia judicial y la garantía de la función constitucional del Consejo. No consuelan el ánimo, ni resuelven el problema artículos como el 578.2 de la ley 4/2013 que despachan la representatividad de los vocales y la proporcionalidad en sus nombramientos con el compromiso de que nuestras Cámaras «tomarán en consideración el número existente en la carrera judicial en el momento de proceder a la renovación». Una consideración que en el actual Consejo tiene sobrerrepresentados los magistrados del Tribunal Supremo y en la posición contraria a los magistrados en general y a los jueces. Y todo ello rematado, respecto de los veinte vocales, con un excesivo perfil judicial que no se limita a los doce así previstos en la ley, sino que sumados a ellos admite, coyunturalmente, que los vocales procedentes del turno de juristas («abogados y otros juristas de reconocida competencia») puedan a su vez ser jueces o magistrados que no estén en activo (art.567.3 ) lo que podría reinterpretar peligrosamente y en el umbral de la «conformidad» la exigencia constitucional del artículo 122.3 de nuestra Carta Magna.

3. La habilitación de un novedoso procedimiento de «renovación a medias» del Consejo, esto es, de tan sólo los vocales que nombra una de las dos Cámaras de nuestro órgano legislativo pudiendo entender que el órgano en su conjunto ha sido renovado y "puede desde entonces ejercer todas sus atribuciones» (entendiendo por todas también el nombramiento del Presidente del Consejo y del Tribunal Supremo), no sólo no regenera y no fortalece nuestra democracia sino que incide muy negativamente granjeando todo tipo de desconfianzas fundadas. Podríamos así permitir un Consejo al servicio de la mayoría de gobierno, de la mayoría parla- 
mentaria, del Ministerio de Justicia. Una especie de prorogatio encubierta o con la cara lavada pero que no es desde luego verdadera renovatio y que augura un funcionamiento carente de legitimidad necesaria. Ensayar nuevas vías como la renovación parcial del órgano (como ocurre por ejemplo para nuestro Tribunal Constitucional) o la articulación de nuevos mecanismos o planes «b» (explicados en páginas anteriores) que impidan admitir la nociva prórroga de mandatos o la inventada «renovación a medias» de nuestros vocales, tal vez podría arrojar alguna idea al servicio de la regeneración democrática en el Consejo.

4. La reforma 4/2013 erradica la obligación de comparecer del Presidente y de todos los vocales antes las Cámaras por razón de sus funciones, fuera de la estricta y mera explicación de la Memoria anual sobre el estado, funcionamiento y actividades del propio Consejo. En tiempos de transparencia, de austeridad, de ajustes de cuentas, de aclaraciones y cercanía al justiciable no parece sensato ni razonable eliminar esta herramienta de control parlamentario que recogen nuestros Reglamentos.

En los últimos días el Consejo aparece en los titulares de los medios de comunicación protagonista en una iniciativa que «desnuda sus cuentas» y se define como «un ejercicio de transparencia sin parangón»y así podemos comprobar lo que cobra el Presidente o un vocal de la permanente. ¿Qué razón, inexistente hasta la fecha, puede justificar la eliminación (antiguo artículo 109.2 de la anterior ley orgánica del Poder Judicial) de las comparecencias de los vocales del Consejo y de su Presidente? La jurisprudencia del TC, y nos remitimos a páginas anteriores de este trabajo, integra en el ius in officium del representante esta herramienta de control, susceptible de utilizarse de modo extensivo, tal como habilita la claúsula final del reglamento parlamentario (art. 44.1 RC). Suprimir esta posibilidad de control de los representantes no sólo podría modificar implícitamente el Reglamento parlamentario, sino afectar el núcleo del 23.2 como derecho fundamental de participación. Pero toda esta reflexión teórica se adereza y refuerza con el rosario de un sinfín de comparecencias vividas por todos los Consejos desde su constitución. Comparecencias que han resultado más esclarecedoras o menos, más necesarias o menos pero que constituyen páginas y páginas de relación Consejo-ciudadanos-representantes sobre las que no se han ofrecido razones o motivos de la oportunidad y conveniencia para su eliminación.

5. El nuevo Consejo disfruta de un nuevo régimen de acuerdos o decisiones. La regla general y salvo excepciones será que el Consejo decida por 
mayoría simple y así nombrará por tal mayoría a los magistrados del TS, a los dos del Tribunal Constitucional y a los cargos judiciales. En definitiva, la mayoría del Consejo podrá decidir sin tener que negociar con las minorías y evitando cualquier potencial bloqueo de las decisiones, además se reduce bastante el número de vocales para entender válidamente constituido el Pleno. Y por último, no parece un gran esfuerzo de regeneración democrática el hecho de que las decisiones y acuerdos de la permanente no sean recurribles ante el Pleno, como sí ocurría en el antiguo art. 143.1 de la LOPJ. Reducir en gran parte el peso decisorio del Consejo a una pequeña Comisión y a la figura del Presidente, entraña importantes riesgos, probablemente no de agilidad en las decisiones, ya que desde luego serán más fáciles de tomar, sino más bien de legitimidad y pluralidad de las mismas pues tan sólo un cuarto de la totalidad del órgano seguirá, conocerá y decidirá el día a día del Consejo.

6. La compatibilidad entre el ejercicio del cargo de vocal del Consejo y el servicio activo como juez o magistrado (además de cualquier otro tipo de actividad profesional o actividad como miembro perteneciente a un grupo de funcionarios, para los vocales procedentes del turno de juristas) es una novedad de este nuevo Consejo y de dudosa constituciona$\operatorname{lidad}^{46}$. El artículo 127.1 de la CE es claro al señalar que jueces y magistrados mientras estén en activo no podrán desempeñar otros cargos públicos. Pero además, la propia redacción de la ley 4/2013, parte de un principio general: la incompatibilidad con cualquier otro cargo público, electivo o no, de los vocales del Consejo y sólo añade bajo el cabecero de «con la sola excepción...», la del servicio al cuerpo al que pertenezcan. Cabe entender que si la razón del constituyente en el 127.1 CE, en aras de garantizar la independencia e imparcialidad de jueces y magistrados, fue establecer la radical incompatibilidad entre

46 El informe del Pleno del CGPJ al Anteproyecto de Ley orgánica del Poder Judicial se pronuncia favorablemente sobre la compatibilidad de vocales y función jurisdiccional o actividad profesional, según cada procedencia. Tal reforma, dice el CGPJ, consigue los objetivos propuestos inicialmente de «eficiencia económica de la institución» y de «mayor relevancia y protagonismo al Cuerpo de Letrados del Consejo». Ahora bien, también denuncia que en la medida en que es obligatorio para los vocales del Pleno y de la Comisión permanente asistir, salvo causa justificada, a las sesiones de aquéllos órganos. La compatibilidad de funciones públicas de los vocales, origina situaciones de coincidencias de vistas de juicios, plenos y otros actos procesales. Por todo ello recomienda el Consejo que debería introducirse por las leyes procesales la posibilidad de contemplar como causa de suspensión de juicios, vistas y otros actos procesales la asistencia a una sesión del Pleno o de una Comisión del CGPJ. 
el ejercicio de cargos públicos y la jurisdicción, no existe justificación para tratar de compatibilizar ambas opciones. Y tampoco existe interpretación razonable para diferenciar que unos vocales sí y otros no, dependiendo de su pertenencia o no a la Comisión permanente. A menos que aceptemos que habrá dos «categorías de vocales», lo que vuelve a pisar la línea roja de la conformidad constitucional con el 122 de la CE.

Es evidente que no todos los vocales tendrán el mismo papel decisorio, el mismo estatus, el mismo grado de implicación y conocimiento de la realidad del Consejo en sus diversas actividades, el mismo sueldo, la misma responsabilidad, etc. En el origen del Consejo como órgano de gobierno de jueces y magistrados está desde luego el respeto al principio de separación de poderes. El Consejo es reflejo, en cierto modo, del Consiglio Superiore della Magistratura de la Constitución italiana de 1947 en el decidido ánimo de separar gobierno y ministerio de Justicia de un numeroso grupo de decisiones neurálgicas del Poder judicial tales como nombramientos, ascensos, sanciones disciplinarias, inspecciones. Y todo ello para blindar y garantizar la independencia de jueces y magistrados en el ejercicio de sus funciones. Pero si volvemos compatibles estos dos cargos públicos, vocales y titulares del poder judicial, ¿no estaremos abriendo la puerta a toda una serie de presiones internas y externas, acosadoras de la necesaria independencia? ¿Por qué unos sí y otros no? Tamaña diferencia no parece quedar suficientemente razonada. La esencia de la «compatibilidad o incompatibilidad» de los vocales con el ejercicio de otros cargos públicos, ¿cómo debe interpretarse? El destino de los vocales (en la Comisión permanente o en otra Comisión), no parece un argumento susceptible de convertir en compatible el ejercicio de dos funciones. Salvo que residenciemos la «compatibilidad» en meros razonamientos de esfuerzo y dedicación, traducidos en horas de trabajo. Si reivindicamos un discurso de la «compatibilidad» que relacione ésta con la independencia judicial de jueces y magistrados (puesto que para el caso de vocales juristas, tal vez el discurso deba ser otro) y con la separación real de poderes, no cabe la regulación que nos propone la ley 4/2013.

Y en este ritmo vertiginoso de reformas y sin saber aún cómo afectarán a este desgastado y desacreditado Consejo, ya atisbamos más cambios. Se han propuesto recientemente por nuestro Gobierno (27 de junio de 2014) en el Anteproyecto de Ley orgánica de reforma del Poder Judicial. Este texto que ha sido favora- 
blemente informado por el pleno del CGPJ con 13 votos favorables y 7 en contra ${ }^{47}$ Un documento que requerirá un seguimiento en su inminente futuro, debate en las Cámaras, enmiendas y tramitación ${ }^{48}$.

\section{BIBLIOGRAFÍA}

Aguiar de Luque, L., «Las recientes reformas en materia de Poder Judicial en su dimensión orgánica» en El Poder Judicial, VI Congreso de la Asociación de Constitucionalistas de España, (Coord. Miguel Revenga) Tirant lo Blanch, Valencia 2009, págs. 17 y ss.

47 Han votado en contra: Roser Bach, Victoria Cinto, Enrique Lucas, Clara Martínez de Careaga, Rafael Mozo, Merçe Pigem y Concepción Sáenz. Con relación al Consejo se introducen algunas propuestas como la posibilidad de reelección a un máximo de cuatro vocales para un segundo mandato El Anteproyecto dedica su Libro IV al Consejo General del Poder Judicial. De entre las principales novedades que se proponen vemos que añade el artículo 466.3: «...El Presidente del TS y del CGPJ y hasta un máximo de cuatro vocales podrán ser reelegidos por un solo mandato adicional.» A su vez, se propone en aras de reforzar la independencia, la posibilidad de que el CGPJ pueda ordenar a quien perturbe o inquiete a los jueces, el inmediato cese en dicha conducta, pues de persistir ésta constituiría un delito contra la Administración de justicia, art. 18: «1. Todos están obligados a respetar la independencia de los jueces. 2. Los jueces que consideres perturbado su sosiego y ecuanimidad o que se sientan inquietados por algún intento de condicionar indebidamente sus decisiones darán cuenta inmediatamente de los hechos al Presidente del su Tribunal y lo pondrán en conocimiento del CGPJ, sin perjuicio de practicar por sí mismos las diligencias indispensables para asegurar la acción de la Justicia y restaurar el orden jurídico [...] 3. El CGPJ podrá ordenar a quien perturbe o inquiete a los Jueces el inmediato cese en dicha conducta. La continuación o reiteración de tal comportamiento tras recibir la orden de cese será constitutiva de delito contra la Administración de Justicia previsto y penado en el apartado 1 del artículo 464 del Código Penal» Este precepto tiene también su reverso en el artículo 19: «Si la perturbación de la independencia afectare a un Juez actuando unipersonalmente, éste podrá solicitar de la correspondiente sala de Gobierno que formen sala con él otros dos Jueces del mismo Tribunal, a los efectos de tramitar y resolver el asunto de que se trate, de acuerdo con lo establecido en el art. 149.»

${ }^{48} \mathrm{El}$ informe del Pleno del CGPJ al anteproyecto ha suscitado varios votos particulares, siete en concreto, sobre diversos aspectos. Algunos de ellos son bastante duros con el sentido y espíritu general de esta reforma: «... ¿Por qué hay que cambiarlo todo y de una sola vez? ¿Qué trabajos y estudios previos, jurídicos, económicos, presupuestarios, sociológicos se han hecho para llegar a esa conclusión? ¿Qué alternativas se han barajado? ¿Con quién se ha hablado de ellas? [...] No es de extrañar, por tanto, que ante esa falta de justificación de una reforma de este calado se haya forjado un rechazo prácticamente unánime de todos y cada uno de los sectores, colectivos y personas que tienen que ver con la Justicia que es lo mismo que decir todo el conjunto de la sociedad. Paradójicamente, la regulación de una materia que, por definición, ha de sustentarse en el consenso político e institucional sobre su necesidad y su contenido básico ha cosechado, hasta ahora, el resultado contrario...» Voto particular de Enrique Lucas Murillo de la Cueva y Merçé Pigem i Palmés. 
- «Una nueva reflexión sobre la prorogatio de los órganos constitucionales. Una discrepancia y algunas puntualizaciones» en Revista Española de Derecho Constitucional, n. ${ }^{\circ} 85$, enero-abril 2009.

— «El gobierno del poder Judicial en la España actual: funciones y disfunciones», Nuevas Políticas Públicas. Anuario multidisciplinar para la modernización de las Administraciones Públicas, n. ${ }^{\circ}$ 5, 2009, págs. 53-76.

Bacigalupo SAggese, M., «La potestad reglamentaria del Consejo General del Poder Judicial», en Derecho Privado y Constitución, n. ${ }^{\circ}$ 17, Enero-diciembre 2003.

Ballester Cardell, M., «El papel del Consejo General del Poder Judicial en defensa de la independencia de los jueces», en El Poder Judicial, VI Congreso de la Asociación de Constitucionalistas de España, (Coord. Miguel Revenga) Tirant lo Blanch, Valencia 2009, págs. 117 y ss.

Barrero Ortega, A., «¿Órgano de gobierno de los jueces o tercera Cámara política en sede judicial?» en El Poder Judicial, VI Congreso de la Asociación de Constitucionalistas de España, (Coord. Miguel Revenga) Tirant lo Blanch, Valencia 2009, págs. 277 y ss.

FERnÁndeZ-Miranda, J., «La potestad reglamentaria del Consejo General del Poder Judicial” en Revista de Administración Pública 189, septiembre-diciembre 2012.

Garoupa, Nuno y Ginsgurg, T., «The comparative Law and Economics of Judicial Councils», University of Illinois College of Law, 2008, paper 96, págs. 1-40.

Gerpe Landín, M., «La composición del Consejo General del Poder Judicial», Revista del Centro de Estudios Constitucionales, n. ${ }^{\circ}$ 9, 1991, págs. 152 y ss.

Gerpe Landín, M. y Cabellos Espierrez, M. A., El gobierno del Poder Judicial en el Estado autonómico. Evolución y perspectivas, en Marcial Pons 2013.

Griffith, J. A. G., The Politics of the Judiciary, Fourth edition, London 1991;

GrIfFITH, J., Judicial Politics since 1920, Institute of contemporary British History, Oxford 1993.

IÑiguez Hernández, D., El fracaso del autogobierno judicial, Civitas/Thomson, Madrid 2008;

Lucas Murillo de la Cueva, P., «El Poder Judicial en Andalucía» en Santiago Muñoz Machado y Manuel Rebollo Puig (directores) Comentarios al Estatuto de Autonomía de Andalucía, Thomson/Civitas, Madrid 2008, págs. 976 y ss.

— «A vueltas con el Consejo General del Poder Judicial» en Nuevas Políticas Públicas: Anuario multidisciplinar para la modernización de las Administraciones Públicas, n. ${ }^{\circ}$, 2009, págs. 77-96.

— «El gobierno del Poder Judicial: los modelos y el caso español», Revista de las Cortes Generales n. ${ }^{\circ}$ 35, Madrid 1995, pág. 216 y ss.

— «Juez, Constitución y Ley» en El Poder Judicial, VI Congreso de la Asociación de Constitucionalistas de España, (Coord. Miguel Revenga) Tirant lo Blanch, Valencia 2009, págs.79 y ss. 
Navas SÁnchez M., Poder Judicial y sistema de fuentes: la potestad normativa del Consejo General del Poder Judicial, Civitas, 2002.

Del Pino Carazo, A., "Comparecencias ante las Comisiones de la Asamblea de Madrid», Revista Parlamentaria de la Asamblea de Madrid, n. ${ }^{\circ}$ 2, diciembre 1999;

Nieto García, A., El desgobierno de los jueces, Edt. Trotta, Madrid 2004.

Porras Ramírez, J. M., «Fundamento, naturaleza, extensión y límites de la potestad reglamentaria del Consejo General del Poder Judicial (a propósito de la nueva regulación introducida por la LO 16/1994, de 8 de noviembre por la que se reforma la LO 6/1985, del Poder Judicial) en Revista de Estudios Políticos, n. 87, CEPC,1995.

Sánchez Barrios, M. I., La elección de los miembros del Consejo General del Poder Judicial español y de sus homólogos europeos, Tirant lo Blanch, Valencia 2007, pág. 213 y ss.

Serra Cristóbal, R., «El Consejo General del Poder Judicial y los nombramientos discrecionales de magistrados», en El Poder Judicial, VI Congreso de la Asociación de Constitucionalistas de España, (Coord. Miguel Revenga) Tirant lo Blanch, Valencia 2009, págs.237 y ss.

- «La elección de los miembros del Consejo General del Poder Judicial. Una propuesta de Consejo más integrador e independiente», Teoría y Realidad Constitucional, N. 31,2013 , págs. 277-322.

STEVENS ROBERT, «The Independence of the Judiciary: the case of England», Southern California Law Review; vol. 72, 1998; págs. 597-624.

Terol Becerra, M., El Consejo General del Poder Judicial, Centro de Estudios Constitucionales, Madrid 1990.

VelázQuez Álvarez, R., «La extravagancia internacional del Consejo General del Poder Judicial» en El Poder Judicial, VI Congreso de la Asociación de Constitucionalistas de España, (Coord. Miguel Revenga) Tirant lo Blanch, Valencia 2009, págs. 295 y ss.

Title:

DEMOCRATIC REGENERATION? THE NEW ORGANIC LAW 4/2013, 28TH JUNE ON REFORM OF THE GENERAL COUNCIL OF THE JUDICIARY.

\section{Summary:}

I. Introduction II. The new organic Law 4/2013, 28th june on reform of General Council of the Judiciary: gestation context reform; a) The Sudoku of the entry into force, b) Specific normative aspects in one organic law, it's has only an article, c) difficult puzzle in 
its development. III. Content of reform: 1. Council competences 2. How to choose its members 3. The new system to renewal the Council 4. Temporary members of General Council of the Judiciary 5. The new structure and distribution of competences between General Council of the Judiciary Organs, in special, its Vice-president: a) A permanent Commission: very strong and very relevant with permanent members, b) A Vice president of Supreme Court like «alter ego» of General Council of the Judiciary President, c) A professionalized Organ with specialists staff, d) the Majority rule in general. The new system of the General Council of the Judiciary Acts. 6. Transformation of the disciplinary Committee. The Promoter of the disciplinary action. IV. Last Reflections...

\title{
Resumen:
}

Este trabajo analiza la nueva ley Orgánica 4/2013, de 28 de junio de reforma del Consejo General del Poder Judicial, órgano de gobierno de jueces y magistrados. La primera parte estudia los problemas de técnica legislativa en la elaboración de la ley y la segunda, los problemas materiales que plantea como: la modificación y reducción de competencias del Consejo y en especial su Potestad reglamentaria, el nuevo sistema para elegir a sus vocales, las nuevas situaciones y licencias en su proceso de renovación que incitan a la no renovación, la posibilidad de estar en activo en la carrera judicial por parte de algunos vocales del Consejo o la nueva estructura y régimen de actuaciones, entre otros. Todos estos cambios se analizan y estudian observando cierta inconstitucionalidad en algunos. No en vano recientemente se ha presentado un Recurso de inconstitucionalidad ante el TC.

\begin{abstract}
:
This research studies the new Basic Law reform, 4/2013, $28^{\text {th }}$ June of the General Council of the Judiciary which is the governing board of Judges and Magistrates. In one first part analyzes the drafting law problems and other second part discusses about essential aspects in Law like: modification and abridgements of its competences, in especial its traditional regulation competency, the new system to select their members, the new ways to renew the Council encouraging not to renew it, the new compatibilities system or too, the new structure and the different system adopting resolutions, among other problems of course. All mentioned aspects are been studied taking into account their possible unconstitutionality, particularly since the Basic Law has been recently appealed to the Constitutional Court.
\end{abstract}




\section{Palabras clave:}

Independencia Judicial, Consejo General del Poder Judicial, Vocal del Consejo, Potestad reglamentaria, Renovación, Servicio activo y compatibilidades, Comisión Permanente.

\section{Key words:}

Judicial Independence, General Council of the Judiciary, member of Council, Regulation Competency, Renewal, active service and compatibilities, Permanent commission. 